Provided for non-commercial research and education use. Not for reproduction, distribution or commercial use.

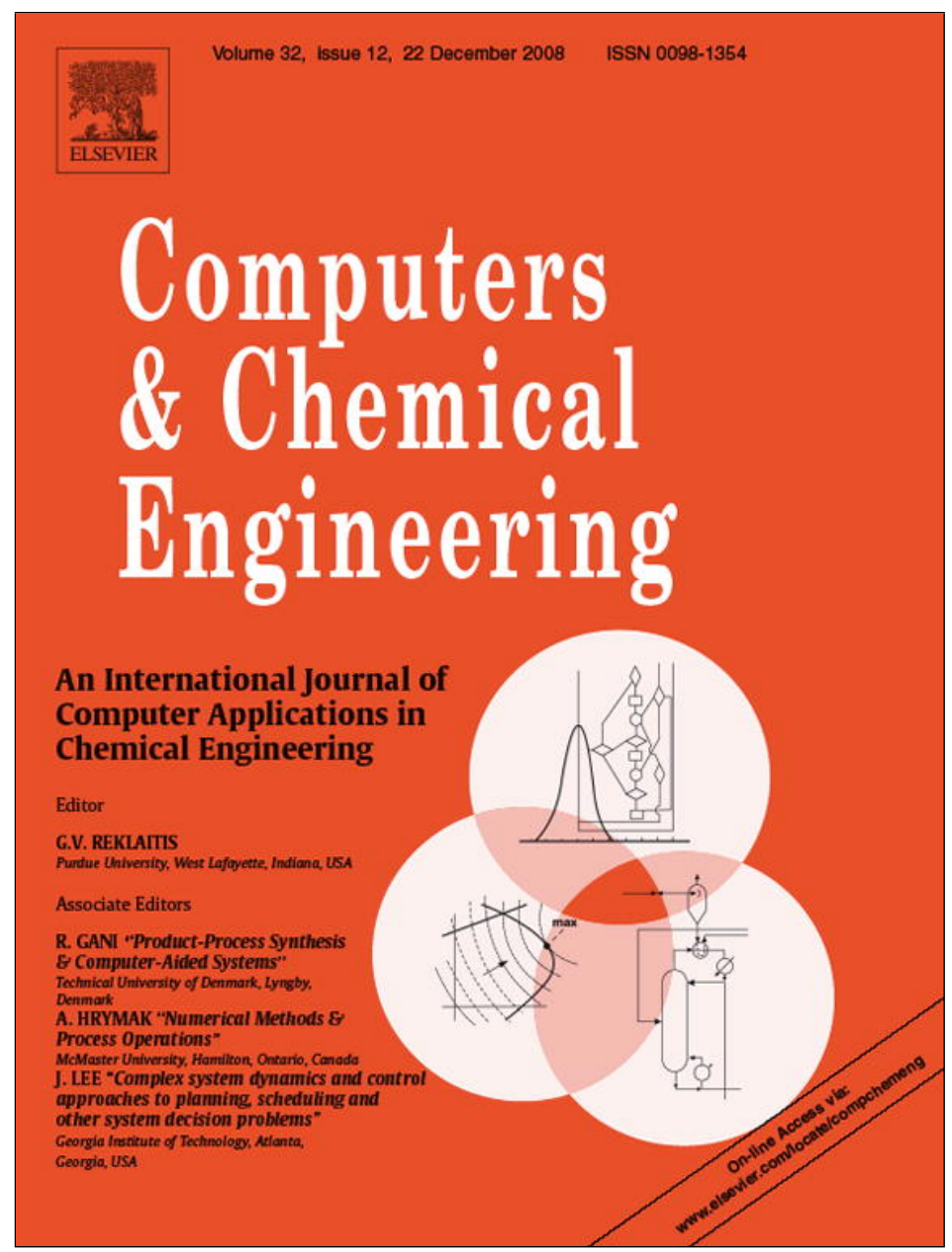

This article appeared in a journal published by Elsevier. The attached copy is furnished to the author for internal non-commercial research and education use, including for instruction at the authors institution and sharing with colleagues.

Other uses, including reproduction and distribution, or selling or licensing copies, or posting to personal, institutional or third party websites are prohibited.

In most cases authors are permitted to post their version of the article (e.g. in Word or Tex form) to their personal website or institutional repository. Authors requiring further information regarding Elsevier's archiving and manuscript policies are encouraged to visit:

http://www.elsevier.com/copyright 


\title{
Control structure design for the ammonia synthesis process
}

\author{
Antonio Araújo, Sigurd Skogestad* \\ Department of Chemical Engineering, Norwegian University of Science and Technology, N-7491 Trondheim, Norway
}

\section{A R T I C L E I N F O}

\section{Article history:}

Received 14 November 2006

Received in revised form 27 February 2008

Accepted 4 March 2008

Available online 13 March 2008

\section{Keywords:}

Ammonia plant

Control structure

Top-down analysis

Bottom-up design

Bottleneck

Throughput

Primary controlled variable

Secondary controlled variables

Manipulable variables

\begin{abstract}
A B S T R A C T
This paper discusses the application of the plantwide control design procedure of Skogestad [Skogestad, S. (2004a). Control structure design for complete chemical plants. Computers and Chemical Engineering, 28, 219-234] to the ammonia synthesis process. Three modes of operation are considered: (I) given feed rate, (IIa) maximum throughput, and (IIb) “optimized" throughput. Two control structures, one for Mode I and another for Mode IIb, are proposed. In Mode I, it is proposed to keep constant purge rate and compressor powers. There is no bottleneck in the process, and thus there is no Mode IIa of operation. In Mode IIb, the compressors are at their maximum capacity and it is proposed to adjust the feed rate such that the inert concentration is constant. The final control structures result in good dynamic performance.
\end{abstract}

(c) 2008 Elsevier Ltd. All rights reserved.

\section{Introduction}

There are hundreds of references on the ammonia synthesis process that discuss the various aspects of its operation and design but none addresses the issue of control structure design in a systematic manner. In this paper, we consider the application of the plantwide control structure design procedure of Skogestad (2004) to an ammonia synthesis process. We start with a top-down analysis of the process where we define the operational objectives (identification of a scalar cost function and operational constraints) and identify the dynamic and steady-state (economic) degrees of freedom. This is followed by the identification of the most important disturbances to the process. Based on all of this information, we proceed by selecting the controlled variables that gives optimal operation (variables that are active at their constraints, Maarleveld \& Rijnsdorp, 1970) and use the self-optimizing control technique (Skogestad, 2000) to decide for the remaining unconstrained controlled variables so that near-optimal operation is achieved without the need to re-optimize when disturbances occur.

One important issue in the plantwide control procedure is the definition on where in the plant the production rate should be set. We distinguish between three modes of operation:

\footnotetext{
* Corresponding author. Fax: +47 73594080.

E-mail addresses: antonio.araujo@chemeng.ntnu.no (A. Araújo), sigurd.skogestad@chemeng.ntnu.no, skoge@chemeng.ntnu.no (S. Skogestad).
}

- Mode I: Given throughput. This mode of operation occurs when (a) the feed rate is given (or limited) or (b) the production rate is given (or limited, e.g. by market conditions). The operational goal is then to minimize utility (energy) consumption, that is, to maximize efficiency.

- Mode II: Throughput as a degree of freedom. We here have two cases:

- Mode Ila: Maximum throughput. This mode encompasses feasibility issues and the maximum throughput does not depend on cost data. It occurs when the product prices are sufficiently high and feed is available.

- Mode IIb: "Optimized" throughput. In some cases, it is not economically optimal to maximize throughput, even if feed is available. This happens if the profit reaches a maximum, for example, because purge streams increase sharply at high feed rates.

The mode in which a given process will operate depends on market conditions, and in which way the plant responds to increasing production rate.

The bottom-up design aims at defining the structure of the regulatory and supervisory control layers. The optimization (RTO) layer is not considered in this paper since we assume that near-optimal operation is satisfactory as long as the loss between the truly optimal and the near-optimal (with constant set point policy for the unconstrained variables) is acceptable. The main purpose of the regulatory control layer is "stabilization" such that the plant does 
not drift far away from its nominal operating point and it also should make the operation of the supervisory control layer smooth such that disturbances on the primary outputs can be handle effectively. The most important issue in the design of the regulatory layer is the selection of good secondary controlled variables and the pairing of these with the inputs at this layer.

With the regulatory layer in place, we then proceed to the design of the supervisory control layer. The purpose of this layer is to keep the primary (economic) controlled variables at their optimal set points using as degrees of freedom (inputs) the set points for the regulatory layer and any unused input at the supervisory layer. The main decisions involved in this layer are related to configuration of the control system, that is, the use of decentralized or multivariable (MPC) control.

A validation step is also included in the procedure in order to evaluate the effectiveness of the proposed control structure against disturbances using dynamic simulation.

For the ammonia plant, we will apply this procedure from a practical perspective in order to illustrate its applicability to actual industrial plants.

To limit the scope of the paper, we have chosen to study the synthesis section separately and do not consider the reaction section of the process. However, for Modes IIa and IIb (feed rate is a degree of freedom), we assume that there is available capacity in the synthesis gas section.

\section{The ammonia synthesis process}

We here consider the ammonia synthesis process given in Fig. 1 which is a simplified version of an actual industrial plant. The reactor configuration is from Morud and Skogestad (1998). The stream table results corresponding to the nominally optimal operating point computed using Aspen ${ }^{\mathrm{TM}}$ are given in Table 1.

Hydrogen and nitrogen are fed to the process at the molar ratio of 3:1 along with a small concentration of inerts (methane and argon). In the synthesis reactor, the following exothermic equilibrium reac- tion (1) takes place:

$\mathrm{N}_{2}+3 \mathrm{H}_{2} \rightleftharpoons 2 \mathrm{NH}_{3}$

We assume that the reaction kinetics are described by the Temkin-Pyzhev kinetics (Froment \& Bischoff, 1990, p. 433) in (2):

$r_{\mathrm{NH}_{3}}=\frac{2 f}{\rho_{\text {cat }}}\left(k_{1} \frac{p_{\mathrm{N}_{2}} p_{\mathrm{H}_{2}}^{1.5}}{p_{\mathrm{NH}_{3}}}-k_{-1} \frac{p_{\mathrm{NH}_{3}}}{p_{\mathrm{H}_{2}}^{1.5}}\right) \quad\left(\mathrm{kmol} \mathrm{NH_{3 }} / \mathrm{kg}\right.$ cat $\left.\mathrm{h}\right)$

with the partial pressure $p_{i}$ in bar and the catalyst bulk density $\rho_{\text {cat }}$ in $\mathrm{kg} / \mathrm{m}^{3}$. The pre-exponential factors of the forward and reverse paths are, respectively:

$k_{1}=1.79 \times 10^{4} \mathrm{e}^{-87,090 / R T}, \quad k_{-1}=2.75 \times 10^{16} \mathrm{e}^{-198,464 / R T}$

where $T$ is the temperature in K. The multiplier factor $f$ is used to correct for the catalyst activity, and we use the value of $f=4.75$ as given in Morud and Skogestad (1998).

The simplified reactor model is shown in Fig. 1. It consists of three adiabatic catalytic reactors (beds) in series with interstage cooling and preheating of the feed with the reactor effluent. The interstage cooling is provided by direct mixing of cold reactor feed with the respective inlet flow to each bed. The beds are modeled in Aspen Plus ${ }^{\mathrm{TM}}$ by means of its built-in catalytic plug-flow reactor model (see the Appendix for more details in the reactor model). This is clearly a simplified model as, e.g. no radial distribution is assumed. However, it is believed to be acceptable for our purposes.

The reactor effluent is quenched in a series of three heat exchangers where the first one $(\mathrm{H}-501)$ uses the hot gases from the reactor to generate low pressure steam. The second heat exchanger (H-502) pre-heats the reactor feed, while the third one (H-583) provides cooling for the condensation of ammonia in the separator (V-502).

The ammonia product, which is about $97 \%(w / w)$ ammonia, leaves the process as a liquid stream through the separator bottom. A small flow is purged from the separator to prevent accumulation of inerts (methane and argon) in the system.

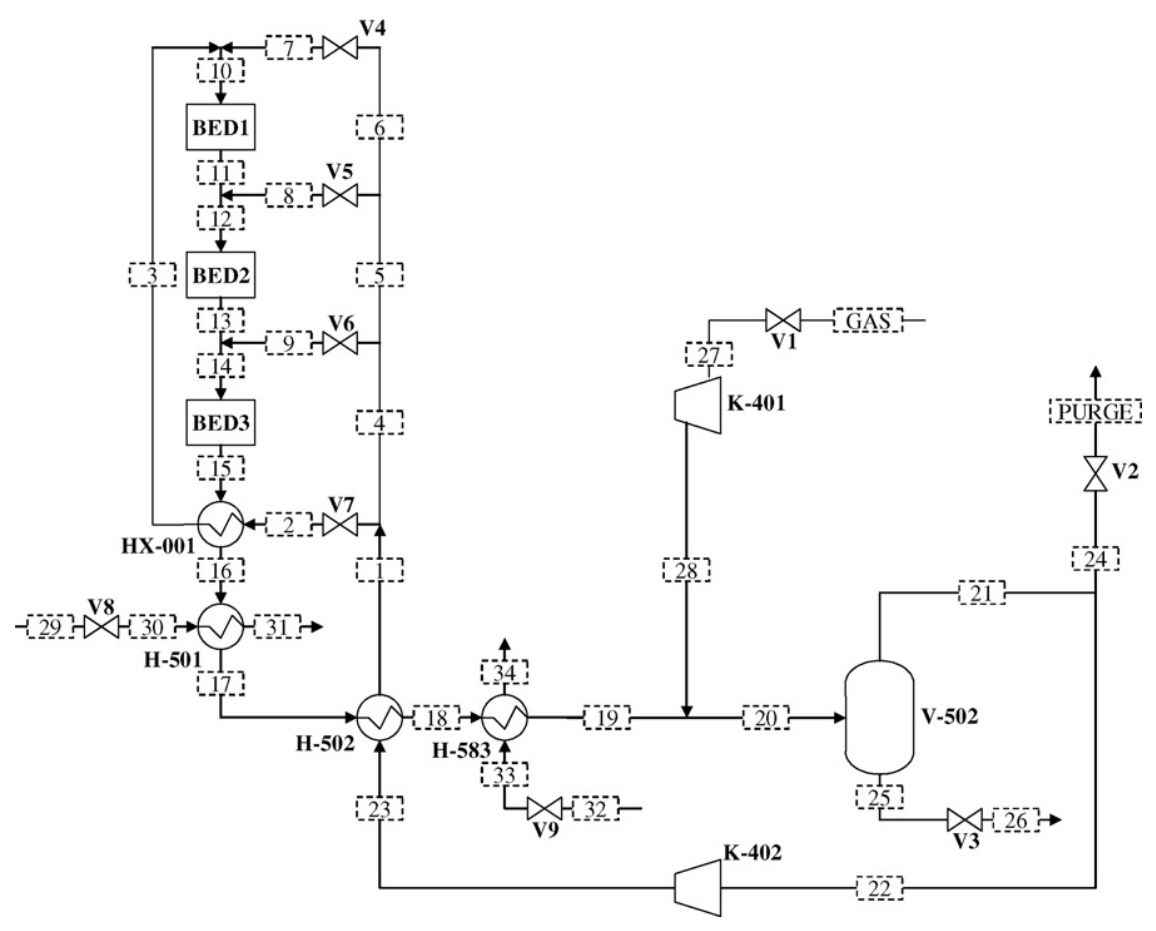

Fig. 1. Ammonia synthesis flowsheet. 
Table 1

Stream table for the nominally optimal operating point for the ammonia synthesis process

\begin{tabular}{|c|c|c|c|c|c|c|c|c|c|c|c|c|c|c|c|c|c|c|}
\hline Stream & 1 & 2 & 3 & 4 & 5 & 6 & 7 & 8 & 9 & 10 & 11 & 12 & 13 & 14 & 15 & 16 & 17 & 18 \\
\hline Temperature $\left({ }^{\circ} \mathrm{C}\right)$ & 231.7 & 231.8 & 340.1 & 231.7 & 231.7 & 231.7 & 231.8 & 231.8 & 231.8 & 306.3 & 456.2 & 420.1 & 452.1 & 423.9 & 449.3 & 394.4 & 296.9 & 107.6 \\
\hline Pressure (bar) & 203.194 & 204.957 & 203.96 & 206.957 & 206.957 & 206.957 & 203.957 & 202.957 & 201.857 & 203.957 & 202.957 & 202.957 & 201.857 & 201.857 & 200.757 & 199.76 & 198.76 & 197.76 \\
\hline Vapor fraction & 1 & 1 & 1 & 1 & 1 & 1 & 1 & 1 & 1 & 1 & 1 & 1 & 1 & 1 & 1 & 1 & 1 & 1 \\
\hline Mole flow (kmol/h) & 40573.8 & 20449.2 & 20449.2 & 5152.87 & 5639.75 & 9331.97 & 9331.97 & 5639.75 & 5152.87 & 29781.2 & 27046.4 & 32686.1 & 32002 & 37154.8 & 36531.7 & 36531.6 & 36531.6 & 36531.6 \\
\hline Mass flow $(\mathrm{kg} / \mathrm{h})$ & 412598 & 207950 & 207950 & 52400 & 57351.2 & 94897.6 & 94897.6 & 57351.2 & 52400 & 302848 & 302848 & 360199 & 360199 & 412599 & 412599 & 412598 & 412598 & 412598 \\
\hline Enthalpy (Mkcal/h) & -22.911 & -11.547 & 5.95 & -2.91 & -3.185 & -5.27 & -5.27 & -3.185 & -2.91 & 0.68 & 0.68 & -2.504 & -2.504 & -5.414 & -5.414 & -22.912 & -53.546 & -112.78 \\
\hline \multicolumn{19}{|l|}{ Mole flow $(\mathrm{kmol} / \mathrm{h})$} \\
\hline Hydrogen & 25329.8 & 12766.2 & 12766.2 & 3216.88 & 3520.84 & 5825.84 & 5825.84 & 3520.84 & 3216.88 & 18592 & 14489.8 & 18010.7 & 16984.4 & 20201.3 & 19266.5 & 19266.5 & 19266.5 & 19266.5 \\
\hline Nitrogen & 7432.32 & 3745.89 & 3745.89 & 943.904 & 1033.09 & 1709.43 & 1709.43 & 1033.09 & 943.904 & 5455.32 & 4087.92 & 5121.01 & 4778.92 & 5722.82 & 5411.25 & 5411.23 & 5411.23 & 5411.23 \\
\hline Methane & 1341.71 & 676.221 & 676.219 & 170.397 & 186.497 & 308.593 & 308.593 & 186.497 & 170.397 & 984.812 & 984.812 & 1171.31 & 1171.31 & 1341.71 & 1341.71 & 1341.7 & 1341.7 & 1341.7 \\
\hline Argon & 943.356 & 475.452 & 475.45 & 119.806 & 131.127 & 216.972 & 216.972 & 131.127 & 119.806 & 692.422 & 692.422 & 823.549 & 823.549 & 943.355 & 943.355 & 943.351 & 943.351 & 943.351 \\
\hline Ammonia & 5526.63 & 2785.42 & 2785.48 & 701.882 & 768.202 & 1271.13 & 1271.13 & 768.202 & 701.882 & 4056.61 & 6791.41 & 7559.61 & 8243.79 & 8945.68 & 9568.82 & 9568.82 & 9568.82 & 9568.82 \\
\hline Water & 0 & 0 & 0 & 0 & 0 & 0 & 0 & 0 & 0 & 0 & 0 & 0 & 0 & 0 & 0 & 0 & 0 & 0 \\
\hline \multicolumn{19}{|l|}{ Mole fraction } \\
\hline Hydrogen & 0.624 & 0.624 & 0.624 & 0.624 & 0.624 & 0.624 & 0.624 & 0.624 & 0.624 & 0.624 & 0.536 & 0.551 & 0.531 & 0.544 & 0.527 & 0.527 & 0.527 & 0.527 \\
\hline Nitrogen & 0.183 & 0.183 & 0.183 & 0.183 & 0.183 & 0.183 & 0.183 & 0.183 & 0.183 & 0.183 & 0.151 & 0.157 & 0.149 & 0.154 & 0.148 & 0.148 & 0.148 & 0.148 \\
\hline Methane & 0.033 & 0.033 & 0.033 & 0.033 & 0.033 & 0.033 & 0.033 & 0.033 & 0.033 & 0.033 & 0.036 & 0.036 & 0.037 & 0.036 & 0.037 & 0.037 & 0.037 & 0.037 \\
\hline Argon & 0.023 & 0.023 & 0.023 & 0.023 & 0.023 & 0.023 & 0.023 & 0.023 & 0.023 & 0.023 & 0.026 & 0.025 & 0.026 & 0.025 & 0.026 & 0.026 & 0.026 & 0.026 \\
\hline Ammonia & 0.136 & 0.136 & 0.136 & 0.136 & 0.136 & 0.136 & 0.136 & 0.136 & 0.136 & 0.136 & 0.251 & 0.231 & 0.258 & 0.241 & 0.262 & 0.262 & 0.262 & 0.262 \\
\hline Water & 0 & 0 & 0 & 0 & 0 & 0 & 0 & 0 & 0 & 0 & 0 & 0 & 0 & 0 & 0 & 0 & 0 & 0 \\
\hline Stream & 19 & 20 & 21 & 22 & 23 & 24 & 25 & 26 & 27 & 28 & 29 & 30 & 31 & 32 & 33 & 34 & Feed & Purge \\
\hline Temperature $\left({ }^{\circ} \mathrm{C}\right)$ & 27.1 & 40.5 & 40.4 & 40.4 & 48 & 40.4 & 40.4 & 40.5 & 17 & 304.2 & 15 & 15.1 & 144.7 & 15 & 15.1 & 82.9 & 17 & 40.2 \\
\hline Pressure (bar) & 196.76 & 196.284 & 195.284 & 195.284 & 207.957 & 195.284 & 195.284 & 190.284 & 23.1 & 196.284 & 10 & 5 & 4 & 10 & 5 & 4 & 23.1 & 190.284 \\
\hline Vapor fraction & 0.81 & 0.907 & 1 & 1 & 1 & 1 & 0 & 0.001 & 1 & 1 & 0 & 0 & 0.456 & 0 & 0 & 0 & 1 & 1 \\
\hline Mole flow (kmol/h) & 36531.6 & 44750.2 & 40578 & 40573.8 & 40573.8 & 4.257 & 4172.14 & 4172.14 & 8218.57 & 8218.57 & 4440.68 & 4440.68 & 4440.68 & 38855.9 & 38855.9 & 38855.9 & 8218.57 & 4.257 \\
\hline Mass Flow $(\mathrm{kg} / \mathrm{h})$ & 412598 & 483598 & 412641 & 412598 & 412598 & 43.294 & 70956.9 & 70956.9 & 71000 & 71000 & 80000 & 80000 & 80000 & 700000 & 700000 & 700000 & 71000 & 43.294 \\
\hline Enthalpy (Mkcal/h) & -164.1 & -148.04 & -84.485 & -84.477 & -82.14 & -0.009 & -63.552 & -63.552 & -0.961 & 16.065 & -306.04 & -306.04 & -275.4 & -2677.8 & -2677.8 & -2626.5 & -0.96 & -0.009 \\
\hline \multicolumn{19}{|l|}{ Mole flow $(\mathrm{kmol} / \mathrm{h})$} \\
\hline Hydrogen & 19266.5 & 25390.2 & 25332.4 & 25329.8 & 25329.8 & 2.658 & 57.707 & 57.707 & 6123.66 & 6123.66 & 0 & 0 & 0 & 0 & 0 & 0 & 6123.66 & 2.658 \\
\hline Nitrogen & 5411.23 & 7454.37 & 7433.11 & 7432.33 & 7432.32 & 0.78 & 21.261 & 21.261 & 2043.14 & 2043.14 & 0 & 0 & 0 & 0 & 0 & 0 & 2043.14 & 0.78 \\
\hline Methane & 1341.7 & 1368.82 & 1341.85 & 1341.71 & 1341.71 & 0.141 & 26.97 & 26.97 & 27.121 & 27.121 & 0 & 0 & 0 & 0 & 0 & 0 & 27.121 & 0.141 \\
\hline Argon & 943.351 & 968.007 & 943.46 & 943.361 & 943.356 & 0.099 & 24.547 & 24.547 & 24.656 & 24.656 & 0 & 0 & 0 & 0 & 0 & 0 & 24.656 & 0.099 \\
\hline Ammonia & 9568.82 & 9568.82 & 5527.16 & 5526.58 & 5526.63 & 0.58 & 4041.66 & 4041.66 & 0 & 0 & 0 & 0 & 0 & 0 & 0 & 0 & 0 & 0.58 \\
\hline Water & 0 & 0 & 0 & 0 & 0 & 0 & 0 & 0 & 0 & 0 & 4440.68 & 4440.68 & 4440.68 & 38855.9 & 38855.9 & 38855.9 & 0 & 0 \\
\hline \multicolumn{19}{|l|}{ Mole fraction } \\
\hline Hydrogen & 0.527 & 0.567 & 0.624 & 0.624 & 0.624 & 0.624 & 0.014 & 0.014 & 0.745 & 0.745 & 0 & 0 & 0 & 0 & 0 & 0 & 0.745 & 0.624 \\
\hline Nitrogen & 0.148 & 0.167 & 0.183 & 0.183 & 0.183 & 0.183 & 0.005 & 0.005 & 0.249 & 0.249 & 0 & 0 & 0 & 0 & 0 & 0 & 0.249 & 0.183 \\
\hline Methane & 0.037 & 0.031 & 0.033 & 0.033 & 0.033 & 0.033 & 0.006 & 0.006 & 0.003 & 0.003 & 0 & 0 & 0 & 0 & 0 & 0 & 0.003 & 0.033 \\
\hline Argon & 0.026 & 0.022 & 0.023 & 0.023 & 0.023 & 0.023 & 0.006 & 0.006 & 0.003 & 0.003 & 0 & 0 & 0 & 0 & 0 & 0 & 0.003 & 0.023 \\
\hline Ammonia & 0.262 & 0.214 & 0.136 & 0.136 & 0.136 & 0.136 & 0.969 & 0.969 & 0 & 0 & 0 & 0 & 0 & 0 & 0 & 0 & 0 & 0.136 \\
\hline Water & 0 & 0 & 0 & 0 & 0 & 0 & 0 & 0 & 0 & 0 & 1 & 1 & 1 & 1 & 1 & 1 & 0 & 0 \\
\hline
\end{tabular}

See Fig. 1 for the stream names. 
Table 2

List of manipulable variables

\begin{tabular}{|c|c|c|}
\hline & Manipulated variable & Status in this work \\
\hline U1 (V1) & Gas feed rate $F_{\text {gas }}(\mathrm{kg} / \mathrm{h})$ & \\
\hline U2 (V2) & Purge flow rate $F_{\text {purge }}(\mathrm{kg} / \mathrm{h})$ & \\
\hline U3 & Feed compressor power $W_{\mathrm{K}-401}(\mathrm{~kW})$ & \\
\hline $\mathrm{U} 4$ & $\begin{array}{l}\text { Recycle compressor power } W_{\mathrm{K}-402} \\
(\mathrm{~kW})\end{array}$ & \\
\hline U5 (V4) & $\begin{array}{l}\text { Interstage cooling flow rate to first bed } \\
F_{\text {bed } 1}(\mathrm{~kg} / \mathrm{h})\end{array}$ & Not used \\
\hline U6 (V5) & $\begin{array}{l}\text { Interstage cooling flow rate to second } \\
\text { bed } F_{\text {bed } 2}(\mathrm{~kg} / \mathrm{h})\end{array}$ & Not used \\
\hline U7 (V6) & $\begin{array}{l}\text { Interstage cooling flow rate to third } \\
\text { bed } F_{\text {bed } 3}(\mathrm{~kg} / \mathrm{h})\end{array}$ & Not used \\
\hline U8 (V8) & $\begin{array}{l}\text { Condensate flow rate to } \mathrm{H}-501 F_{\text {cond }} \\
(\mathrm{kg} / \mathrm{h})\end{array}$ & Not used (at maximum) \\
\hline U9 (V9) & $\begin{array}{l}\text { Cooling water flow rate to } \mathrm{H}-583 F_{\text {cool }} \\
(\mathrm{kg} / \mathrm{h})\end{array}$ & Not used (at maximum) \\
\hline U10 (V3) & Product flow rate $F_{\text {prod }}(\mathrm{kg} / \mathrm{h})$ & Dynamic (level control) \\
\hline
\end{tabular}

Our reactor model did not produce the oscillations found, for example, by Morud and Skogestad (1998). It would have be proper to include a more detailed reactor model, which is open-loop unstable, but this would not change the main results in this paper on selection of controlled variables, because they are based on the steady-state economics.

Next, we apply the control structure design procedure of Skogestad (2004) to the ammonia synthesis process just described, starting with the degree of freedom analysis.

\section{Top-down analysis}

\subsection{Degree of freedom (DoF) analysis}

The ammonia synthesis in Fig. 1 has 10 manipulated variables (Table 2 ) and 11 candidate measurements (Table 4).

Based on the steady-state degree of freedom analysis described in Skogestad (2002), we consider nine steady-state degrees of freedom for optimization as given in Table 3. This is in accordance with Table 2 , because U10 only has a dynamic effect.

Note that we later, in the selection of controlled variables, do not consider the interstage cooling flow rates to the beds as steadystate degrees of freedom, and thus manipulated variables U5-U7 are not used. More precisely, we fix the split fractions U5 and U6 at their nominal optimum values (found from the optimization). This is in accordance with the industrial practice. Moreover, we can anticipate that maximum cooling is optimal in heat exchangers $\mathrm{H}-501$ and $\mathrm{H}-583$ (active constraints) since a small temperature in the separator (V-502) favors more ammonia recovery and less power consumption in the recycle compressor (K-402). Thus, we have four remaining steady-state degrees of freedom (U1-U4) for

Table 3

Steady-state degrees of freedom analysis for the ammonia synthesis plant

\begin{tabular}{|c|c|c|c|}
\hline Process unit & No. of units & DoF/unit & DoF \\
\hline External feed streams & 1 & 1 & 1 \\
\hline Splitters (purge) ${ }^{\mathrm{a}}$ & 1 & 1 & 1 \\
\hline Splitters (cold shots reactor) & 3 & 1 & 3 \\
\hline Compressors (K-401 and K-402) & 2 & 1 & 2 \\
\hline Adiabatic flashes ${ }^{\mathrm{a}}(\mathrm{V}-502)$ & 1 & 0 & 0 \\
\hline Gas phase reactors $^{\mathrm{a}}$ & 3 & 0 & 0 \\
\hline Heat exchangers ${ }^{\mathrm{b}}(\mathrm{H}-501$ and $\mathrm{H}-583)$ & 2 & 1 & 2 \\
\hline Total & & & 9 \\
\hline
\end{tabular}

a Assuming no adjustable valves for pressure control (assume fully open valve before separator).

b We will see later that its is optimal to keep maximum cooling.
Table 4

Selected candidate controlled variables

\begin{tabular}{ll}
\hline Y1 & Gas feed rate $F_{\text {gas }}(\mathrm{kg} / \mathrm{h})$ \\
Y2 & Reactor inlet pressure $P_{\text {rin }}(\mathrm{bar})$ \\
Y3 & Feed compressor power $W_{\mathrm{K}-401}(\mathrm{~kW})$ \\
Y4 & Recycle compressor power $W_{\mathrm{K}-402}(\mathrm{~kW})$ \\
Y5 & Product purity $x_{\mathrm{NH}}$ \\
Y6 & Purge flow rate $F_{\text {purge }}(\mathrm{kg} / \mathrm{h})$ \\
Y7 & Mole fraction of hydrogen $y_{\mathrm{H}_{2}, \text { purge }}$ in the purge stream \\
Y8 & Mole fraction of nitrogen $y_{\mathrm{N}_{2}, \text { purge in the purge stream }}$ \\
Y9 & Mole fraction of ammonia $y_{\mathrm{NH}_{3}, \text { purge in the purge stream }}$ \\
Y10 & Mole fraction of argon $y_{\mathrm{Ar}, \text { purge }}$ in the purge stream \\
Y11 & Mole fraction of methane $y_{\mathrm{CH}_{4}, \text { purge }}$ in the purge stream \\
\hline
\end{tabular}

which we need to find an associated controlled variable. Note that for case I with a given feedrate (U1 given), we only need to find three controlled variables.

Table 4 lists the 11 candidate controlled variables considered in this study. With 4 steady-state degrees of freedom and 11 candidate measurements, there are $\left(\begin{array}{c}11 \\ 4\end{array}\right)=11 ! / 4 ! 7 !=660$ possible ways of selecting the control structure. This shows that we need a simple tool to pre-screen and identify good candidate structures. An effective tool, used in this paper, for the case with unconstrained degrees of freedom is to consider the minimum singular value of the steady-state gain matrix. A large value means that controlling the associated controlled variables has good "self-optimizing" properties.

\subsection{Definition of optimal operation}

The operational objective to be maximized is given by the profit $P$ below:

$$
\begin{aligned}
P= & \$_{\text {prod }}\left(x_{\mathrm{NH}_{3}} F_{\text {prod }}\right)+\$_{\text {purge }} F_{\text {purge }}+\$_{\text {steam }} F_{\text {steam }}-\$_{\text {gas }} F_{\text {gas }} \\
& -\$_{\mathrm{ws}}\left(W_{\mathrm{K}-401}+W_{\mathrm{K}-402}\right)
\end{aligned}
$$

where $x_{\mathrm{NH}_{3}}$ is the product purity and $F_{\text {steam }}$ is the steam generation in $\mathrm{kg} / \mathrm{h}$. Note that $P$ is the operational profit and does not include other fixed costs or capital costs.

The prices are $\$_{\text {prod }}=0.200 \$ / \mathrm{kg}, \$_{\text {purge }}=0.010 \$ / \mathrm{kg}, \$_{\text {steam }}=$ $0.017 \$ / \mathrm{kg}$, $\$$ gas $=0.080 \$ / \mathrm{kg}$, and $\$$ ws $=0.040 \$ / \mathrm{kJ}$.

The constraints on operation are

$P_{\text {rin }} \leq 250$ bar

$W_{\mathrm{K}-401} \leq 25,000 \mathrm{~kW}$

$W_{\mathrm{K}-402} \leq 3500 \mathrm{~kW}$

$F_{\text {cond }} \leq 80,000 \mathrm{~kg} / \mathrm{h}$

$F_{\text {cool }} \leq 700,000 \mathrm{~kg} / \mathrm{h}$

Nominally, we have $F_{\text {gas }}=71,000 \mathrm{~kg} / \mathrm{h}, P_{\text {rin }}=203 \mathrm{bar}, W_{\mathrm{K}-401}=$ $19,800 \mathrm{~kW}, W_{\mathrm{K}-402}=2718 \mathrm{~kW}$, and the molar feed compositions $y_{\mathrm{H}_{2}}=0.7450, y_{\mathrm{N}_{2}}=0.2486, y_{\mathrm{CH}_{4}}=0.0033$, and $y_{\mathrm{AR}}=0.0030$, as given in Table 1.

We now proceed the self-optimizing control analysis for the cases with given feed rate and variable feed rate, separately.

\subsection{Operation with given feed rate}

\subsubsection{Identification of important disturbances}

For the case with given gas feed rate $F_{\text {gas }}$, we consider the disturbances listed in Table 5. 
Table 5

Disturbances to the process operation for Mode I

\begin{tabular}{lllc}
\hline No. & Description & Nominal & Disturbance \\
\hline D1 & Gas feed rate $(\mathrm{kg} / \mathrm{h})$ & 71,000 & $+15 \%$ \\
D2 & Gas feed rate $(\mathrm{kg} / \mathrm{h})$ & 71,000 & $-15 \%$ \\
D3 & Split fraction to the first bed & 0.230 & $+0.1^{\mathrm{a}}$ \\
D4 & Split fraction to the second bed & 0.139 & $+0.1^{\mathrm{a}}$ \\
D5 & Split fraction to the third bed & 0.127 & $+0.1^{\mathrm{a}}$ \\
D6 & Mole fraction of $\mathrm{CH}_{4}$ in the gas feed & 0.0033 & $+0.0030^{\mathrm{b}}$ \\
D7 & Mole fraction of Ar in the gas feed & 0.0030 & $+0.0030^{\mathrm{b}}$ \\
\hline
\end{tabular}

a The split fraction to the feed effluent heat exchanger is reduced by the same amount.

b Mole fraction of $\mathrm{H}_{2}$ in the gas feed is reduced by the same amount.

\subsubsection{Optimization}

With a given gas feed rate $F_{\text {gas, }}$, there are eight steady-state degrees of freedom for optimization, namely $F_{\text {purge }}, W_{\mathrm{K}-401}, W_{\mathrm{K}-402}$, $F_{\text {cond }}$, and $F_{\text {cool }}$, plus the three split fractions in the reactor. Fig. 2 gives the results of the optimizations conducted in Aspen Plus ${ }^{\mathrm{TM}}$ for the nominal operating point and for the seven disturbances described in Table 5 . As it can be seen, the profit $P$ is weakly dependent on the disturbances, except for disturbances D1 and D2 that have a large effect on $P$. However, note that the fact that a disturbance has a small effect on the profit does not mean it can be discarded when selecting the controlled variables.

As mentioned, during operating we fix the reactor inlet temperature plus the two splits for the reactor cooling at their nominal values. Furthermore, we found that the two cooling duties $\left(F_{\text {cond }}\right.$ and $F_{\text {cool }}$ ) are optimal at their upper constraints, so these should be implemented as active constraints (two variables). This leaves $5-2=3$ unconstrained degrees of freedom $\left(W_{\mathrm{K}-401}, W_{\mathrm{K}-402}\right.$, and $\left.F_{\text {purge }}\right)$ for which we need to identify associated controlled variables.

\subsubsection{Identification of candidate controlled variables-local} analysis

Because of the large number of candidate structures, we first pre-screen using a local (linear) analysis as described in Skogestad and Postlethwaite (2005). The objective is to find the set of three unconstrained controlled variables that maximizes the minimum singular value $\sigma\left(S_{1} G J_{u u}^{-1 / 2}\right)$. $G$ is the steady-state gain matrix of the process from the three unconstrained degrees of freedom $u$ to the candidate controlled variables in Table 4 (variables Y2-Y11); Juи is the Hessian (second-order derivative) of the profit function (4) with respect to the three steady-state degrees of freedom $u$. The motivation behind this expression is that it gives a measure of the loss when a set of candidate controlled variables is fixed at the nominal setpoint in a neighborhood around the nominal optimum. $S_{1}$ is the matrix of scalings for the candidate measurements $S_{1}=\operatorname{diag}\left\{1 / \operatorname{span}\left(Y_{i}\right)\right\}$. span $\left(Y_{i}\right)$ is the variation of each candidate

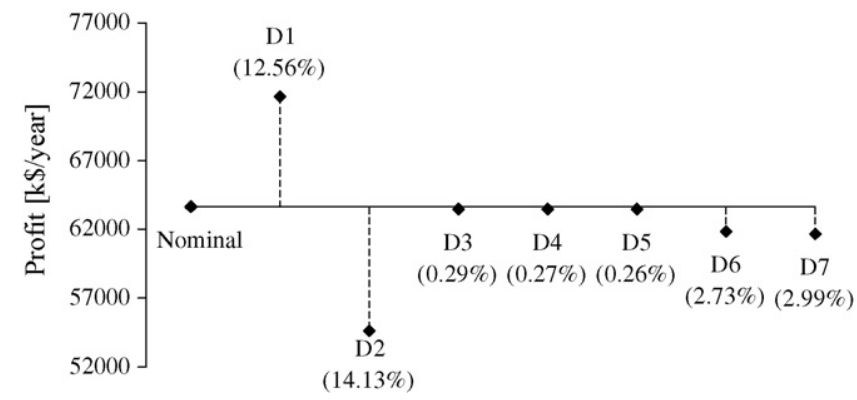

Fig. 2. Effect of disturbances (see Table 5) on optimal operation for Mode I. Percentages in parentheses are the changes with respect to the nominally optimum.
Table 6

Optimal variation for the candidate controlled variables for Mode I

\begin{tabular}{|c|c|c|c|c|c|}
\hline & Description & Nominal & $\Delta Y_{i, \mathrm{opt}}(d)$ & $n_{i}$ & $\operatorname{span}\left(Y_{i}\right)$ \\
\hline Y2 & Reactor inlet pressure $P_{\text {rin }}$ (bar) & 203 & 35 & 5 & 40 \\
\hline Y3 & $\begin{array}{l}\text { Feed compressor power } W_{\mathrm{K}-401} \\
(\mathrm{~kW})\end{array}$ & 19,800 & 5200 & 1000 & 6200 \\
\hline Y4 & $\begin{array}{l}\text { Recycle compressor power } \\
W_{\mathrm{K}-402}(\mathrm{~kW})\end{array}$ & 2718 & 782 & 100 & 882 \\
\hline Y5 & Product purity $x_{\mathrm{NH}_{3}}$ & 0.969 & 0.015 & 0.01 & 0.025 \\
\hline Y6 & Purge flow rate $F_{\text {purge }}(\mathrm{kg} / \mathrm{h})$ & 43.29 & 673 & 5 & 678 \\
\hline Y7 & Mole fraction of hydrogen & 0.624 & 0.069 & 0.05 & 0.119 \\
\hline Y8 & $\begin{array}{l}y_{\mathrm{H}_{2} \text {,purge in the purge stream }} \\
\text { Mole fraction of nitrogen }\end{array}$ & 0.183 & 0.044 & 0.03 & 0.074 \\
\hline Y9 & $\begin{array}{l}y_{\mathrm{N}_{2} \text {,purge in the purge stream }} \\
\text { Mole fraction of ammonia }\end{array}$ & 0.136 & 0.016 & 0.03 & 0.046 \\
\hline Y10 & $\begin{array}{l}y_{\mathrm{NH}_{3}, \text { purge }} \text { in the purge stream } \\
\text { Mole fraction of argon } y_{\mathrm{Ar} \text {,purge }} \\
\text { in the purge stream }\end{array}$ & 0.023 & 0.023 & 0.002 & 0.025 \\
\hline Y11 & $\begin{array}{l}\text { Mole fraction of methane } \\
y_{\mathrm{CH}_{4} \text {,purge }} \text { in the purge stream }\end{array}$ & 0.033 & 0.028 & 0.003 & 0.031 \\
\hline
\end{tabular}

controlled variable $Y_{i}$ due to variation in disturbances and implementation error $n_{i}$ :

$\operatorname{span}\left(Y_{i}\right)=\Delta Y_{i, \mathrm{opt}}+n_{i}=\sum_{j}\left|\frac{\partial Y_{i}}{\partial d_{j}}\right| \Delta d_{j}+n_{i}$

In Table 6, we give the optimal variation and implementation error for the candidate controlled variables in Table 4 . A branch-andbound algorithm (Cao \& Kariwala, 2008) is used to obtain the candidate sets of controlled variables. The results for the ten sets with largest $\underline{\sigma}\left(S_{1} G J_{u u}^{-1 / 2}\right)$ are shown in Table 7 . One candidate set that one may expect is good is to control reactor inlet pressure $P_{\text {rin }}$, feed compressor power $W_{\mathrm{K}-401}$, and mole fraction of methane in

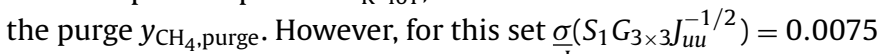
which is about 10 times smaller than set $\mathrm{S}_{9}{ }^{\bar{I}}$, and we expect the loss be about $10^{2}=100$ times larger.

As we can see from Table 7, it is desirable to keep the purge flow rate (candidate controlled variable Y6) fixed at its nominally optimal set point. The other two controlled variables may be "freely" chosen among any of the 10 sets in Table 7 because $\underline{\sigma}\left(S_{1} G_{3 \times 3} J_{u u}^{-1 / 2}\right)$ is essentially the same. As an attractive option, we choose to keep the variables in set $\mathrm{S}_{9} \mathrm{I}$ (feed compressor power $W_{\mathrm{K}-401}$, recycle compressor power $W_{\mathrm{K}-402}$, and purge flow rate $\left.F_{\text {purge }}\right)$ at their nominally optimal set point since this reduces significantly the complexity of the control structure.

\subsubsection{Evaluation of loss}

We now evaluate in more detail the loss caused by keeping each controlled variable in set $S_{9}{ }^{I}$, corresponding to Mode I of operation, at its nominally optimal set point. The results are shown in Table 8.

Table 7

Local analysis (Mode I): minimum singular values for the 10 best sets of unconstrained controlled variables

\begin{tabular}{|c|c|c|c|c|}
\hline \multirow{2}{*}{$\frac{\text { Set }}{S_{1}{ }^{I}}$} & \multicolumn{3}{|c|}{ Variables } & \multirow{2}{*}{$\frac{\underline{\sigma}\left(S_{1} G_{3 \times 3} J_{u u}^{-1 / 2}\right)}{0.07652}$} \\
\hline & Y6 & Y8 & Y2 & \\
\hline $\mathrm{S}_{2}{ }^{\mathrm{I}}$ & Y6 & Y11 & Y4 & 0.07534 \\
\hline $\mathrm{S}_{3} \mathrm{I}$ & Y6 & Y3 & Y10 & 0.07512 \\
\hline $\mathrm{S}_{4} \mathrm{I}$ & Y6 & Y3 & $\mathrm{Y} 2$ & 0.07502 \\
\hline $\mathrm{S}_{5} \mathrm{I}$ & Y6 & Y3 & Y7 & 0.07501 \\
\hline $\mathrm{S}_{6} \mathrm{I}$ & Y6 & Y3 & Y9 & 0.07491 \\
\hline $\mathrm{S}_{7}^{\mathrm{I}}$ & Y6 & Y8 & Y3 & 0.07490 \\
\hline $\mathrm{S}_{8} \mathrm{I}$ & Y6 & Y3 & Y5 & 0.07489 \\
\hline $\mathrm{S}_{9}^{\mathrm{I}}$ & Y6 & Y3 & Y4 & 0.07485 \\
\hline $\mathrm{S}_{10} \mathrm{I}$ & Y6 & Y2 & Y9 & 0.07478 \\
\hline
\end{tabular}


Table 8

Loss by keeping the variables in set $\mathrm{S}_{9}{ }^{\mathrm{I}}$ in Table 7 at their nominally optimal set points for Mode I

\begin{tabular}{lccl}
\hline Disturbance & Optimal profit (k\$year) & Profit with $\mathrm{S}_{9}{ }^{\mathrm{I}}$ (k\$/year) & Loss (k\$/year) \\
\hline D1 & 71,616 & 71,228 & 388 \\
D2 & 54,631 & 53,734 & 897 \\
D3 & 63,437 & 63,203 & 234 \\
D4 & 63,450 & 63,198 & 252 \\
D5 & 63,458 & 63,191 & 267 \\
D6 & 61,886 & 61,400 & 485 \\
D7 & 61,723 & 61,603 & 120 \\
Average & & & 378 \\
\hline
\end{tabular}

As the average loss is considered acceptable, we confirm that set $\mathrm{S}_{9}{ }^{\mathrm{I}}$ an acceptable set of primary controlled variables for the case with given gas feed rate (Mode I).

\subsection{Operation with variable feed rate}

\subsubsection{Maximum throughput}

From an economic point of view, it is optimal to increase the production rate $F_{\text {prod. }}$. With the given feed rate as a parameter, we optimize the profit $P$ in (4) with the same constraints (5)-(9). The results are given in Fig. 3. As per Mode I, the steady-state optimization was performed with all nine steady-state degrees of freedom, including here the inlet temperature to the reactor $\left(F_{\text {bed1 } 1}\right)$ and the split fractions to the three interstage cooling flows $\left(F_{\text {bed2 }}\right.$ and $\left.F_{\text {bed3 } 3}\right)$, but we then fix $F_{\text {bed } 1}$ to $F_{\text {bed3 }}$ at their nominally optimal values.

When $F_{\text {gas }}=71,850 \mathrm{~kg} / \mathrm{h}$, the constraint (7) on the recycle compressor power $\left(W_{\mathrm{K}-402}\right)$ becomes active and remains active as the feed is increased. When $F_{\text {gas }}=80,400 \mathrm{~kg} / \mathrm{h}$, constraint (6) on the feed compressor power $\left(W_{\mathrm{K}-401}\right)$ becomes active and also remains active. Around $F_{\text {gas }}=87,250 \mathrm{~kg} / \mathrm{h}$, the profit reaches its maximum and then it starts falling sharply. The reason for the drop is the reduction in pressure which reduces the conversion and results in a sharp increase in the purge flow rate (see Fig. 4). Note that the degrees of freedom corresponding to condensate flow rate to $\mathrm{H}$ $501, F_{\text {cond }}$, and cooling water flow rate to H-583, $F_{\text {cool }}$, were found to be active throughout the optimizations.

Note that there is no bottleneck and thus no maximum throughput (Mode IIa) for this case study. The reason is that the feed may be purged and there is no limit on the purge rate.

On the other hand, there is an "optimized" throughput (Mode IIb) corresponding to an "economic" bottleneck where $\partial P / \partial F_{\text {gas }}=0$ and further increase in $F_{\text {gas }}$ leads to non-optimal economic operation.

\subsubsection{Optimization (Mode IIb)}

We now evaluate the optimal operation with the gas feed rate as a degree of freedom and the two compressors at their constraints,

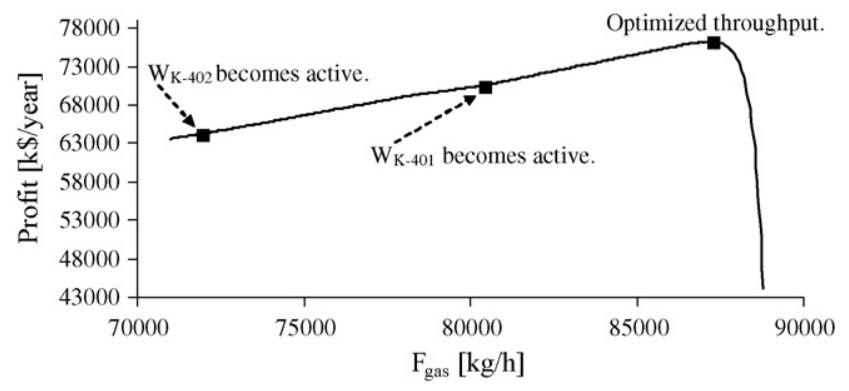

Fig. 3. Optimization of the ammonia plant with variable gas feed rate $F_{\text {gas }}$.

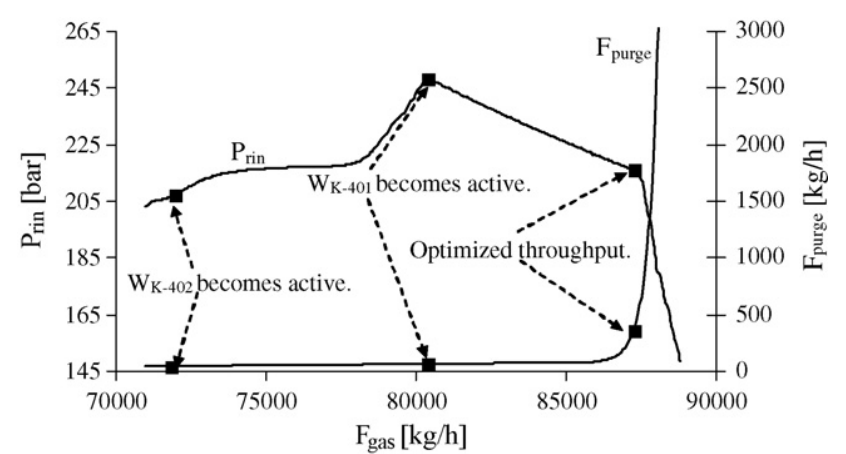

Fig. 4. Optimal reactor inlet pressure $P_{\text {rin }}$ and purge flow rate $F_{\text {purge }}$ as a function of gas feed rate $F_{\text {gas. }}$.

Table 9

Disturbances to the process operation for Mode IIb

\begin{tabular}{llll}
\hline No. & Description & Nominal & Disturbance \\
\hline D3 & Split fraction to the first bed & 0.230 & $+0.1^{\mathrm{a}}$ \\
D4 & Split fraction to the second bed & 0.139 & $+0.1^{\mathrm{a}}$ \\
D5 & Split fraction to the third bed & 0.127 & $+0.1^{\mathrm{a}}$ \\
D6 & Mole fraction of $\mathrm{CH}_{4}$ in the gas feed & 0.0033 & $+0.003^{\mathrm{b}}$ \\
D7 & Mole fraction of $A r$ in the gas feed & 0.0030 & $+0.003^{\mathrm{b}}$ \\
D8 & Feed compressor power $W_{\mathrm{K}-401}(\mathrm{~kW})$ & 25,000 & +1000 \\
D9 & Recycle compressor power $W_{\mathrm{K}-402}(\mathrm{~kW})$ & 3500 & +100 \\
\hline
\end{tabular}

a The split fraction to the feed effluent heat exchanger is reduced by the same amount.

b Mole fraction of $\mathrm{H}_{2}$ in the gas feed is reduced by the same amount.

i.e. $W_{\mathrm{K}-401}=25,000 \mathrm{~kW}$ and $W_{\mathrm{K}-401}=3500 \mathrm{~kW}$, respectively. There are two remaining unconstrained degrees of freedom for which we need to identify controlled variables, namely the gas feed rate $F_{\text {gas }}$ and the purge flow rate $F_{\text {purge. }}$. We thus perform optimization runs for the disturbances listed in Table 9 below. The results are shown in Fig. 5.

\subsubsection{Identification of candidate controlled variables-local analysis}

We use a linear analysis, similar to the one conducted in Section 3.3.3, to pre-screen the candidate controlled variables in Table 4.

The optimal variation and implementation error are given in Table 10 and the ten best sets with largest $\underline{\sigma}\left(S_{1} G J_{u u}^{-1 / 2}\right)$ are shown in Table 11.

From Table 11, we see that the five best sets involve control of reactor pressure (Y2), which is easy to control. The other controlled variable (Y7-Y11) is a composition. The lowest minimum singular value is for methane (Y11) and we consider this in more detail in the following.

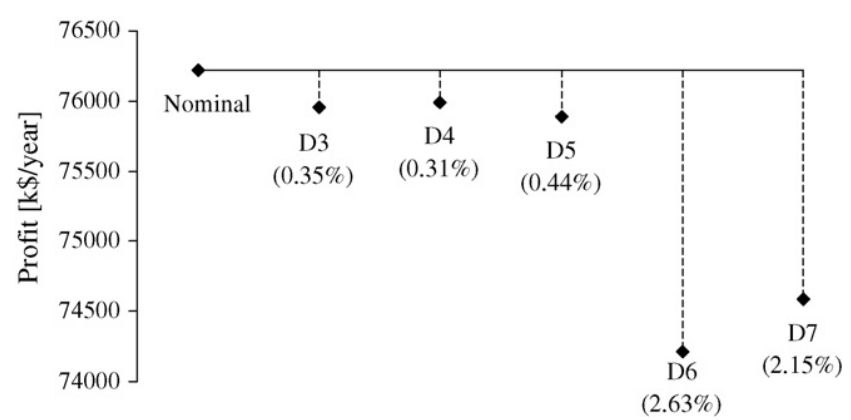

Fig. 5. Effect of disturbances (see Table 9) on optimal operation for Mode IIb. Percentages in parentheses are the changes with respect to the nominally optimum. 
Table 10

Total span summary for the candidate controlled variables for Mode IIb

\begin{tabular}{|c|c|c|c|c|c|}
\hline & Description & Nominal & $\Delta Y_{i, \mathrm{opt}}(d)$ & $n_{i}$ & $\operatorname{span}\left(Y_{i}\right)$ \\
\hline Y1 & Gas feed rate $F_{\text {gas }}(\mathrm{kg} / \mathrm{h})$ & 87,250 & 1570 & 1700 & 3315 \\
\hline Y2 & Reactor inlet pressure $P_{\text {rin }}$ (bar) & 226 & 68 & 5 & 73 \\
\hline Y5 & Product purity $x_{\mathrm{NH}_{3}}$ & 0.968 & 0.019 & 0.01 & 0.029 \\
\hline Y6 & Purge flow rate $F_{\text {purge }}(\mathrm{kg} / \mathrm{h})$ & 366 & 22,348 & 36.6 & 22384.5 \\
\hline Y7 & Mole fraction of hydrogen & 0.603 & 0.068 & 0.05 & 0.118 \\
\hline Y8 & $\begin{array}{l}y_{\mathrm{H}_{2} \text {,purge in the purge stream }} \\
\text { Mole fraction of nitrogen }\end{array}$ & 0.174 & 0.040 & 0.03 & 0.070 \\
\hline Y9 & $\begin{array}{l}y_{\mathrm{N}_{2}, \text { purge }} \text { in the purge stream } \\
\text { Mole fraction of ammonia }\end{array}$ & 0.172 & 0.019 & 0.03 & 0.049 \\
\hline Y10 & $\begin{array}{l}y_{\mathrm{NH}_{3} \text {,purge in the purge stream }} \\
\text { Mole fraction of argon } y_{\mathrm{Ar} \text {,purge }} \\
\text { in the purge stream }\end{array}$ & 0.022 & 0.027 & 0.002 & 0.029 \\
\hline Y11 & $\begin{array}{l}\text { Mole fraction of methane } \\
y_{\mathrm{CH}_{4} \text {,purge in the purge stream }}\end{array}$ & 0.029 & 0.025 & 0.003 & 0.028 \\
\hline
\end{tabular}

Table 11

Local analysis (Mode IIb): minimum singular values for the ten best sets of unconstrained controlled variables

\begin{tabular}{|c|c|c|c|}
\hline \multirow{2}{*}{$\frac{\text { Set }}{\mathrm{S}_{1}{ }^{\mathrm{IIb}}}$} & \multicolumn{2}{|c|}{ Variables } & \multirow{2}{*}{$\begin{array}{l}\underline{\sigma}\left(S_{1} G_{2 \times 2} J_{u u}^{-1 / 2}\right) \\
0.07011\end{array}$} \\
\hline & Y2 & Y11 & \\
\hline $\mathrm{S}_{2}{ }^{\mathrm{Ilb}}$ & Y2 & Y10 & 0.06809 \\
\hline $\mathrm{S}_{3}{ }^{\mathrm{Ilb}}$ & Y2 & Y8 & 0.06510 \\
\hline $\mathrm{S}_{4}{ }^{\mathrm{Ilb}}$ & Y2 & Y9 & 0.06391 \\
\hline $\mathrm{S}_{5}{ }^{\mathrm{Ilb}}$ & Y2 & Y7 & 0.05913 \\
\hline $\mathrm{S}_{6}{ }^{\mathrm{IIb}}$ & Y7 & Y8 & 0.05022 \\
\hline $\mathrm{S}_{7}{ }^{\mathrm{IIb}}$ & Y7 & Y10 & 0.04599 \\
\hline $\mathrm{S}_{8}{ }^{\mathrm{Ilb}}$ & Y7 & Y11 & 0.04172 \\
\hline $\mathrm{S}_{9}^{\mathrm{IIb}}$ & Y9 & Y5 & 0.03987 \\
\hline $\mathrm{S}_{10}{ }^{\mathrm{Ilb}}$ & Y10 & Y11 & 0.03429 \\
\hline
\end{tabular}

Note that the purge flow rate (Y6) is not included in any of the ten best sets, whereas it was included in all the ten best sets in Mode I (with given feed).

\subsubsection{Evaluation of loss (Mode IIb)}

The loss is calculated is calculated for set $\mathrm{S}_{1}{ }^{\mathrm{IIb}}$ and given in Table 12 for various disturbances.
As the average loss for Mode IIb is acceptable, we confirm set $\mathrm{S}_{1}$ IIb in Table 11 as the selected set of primary controlled variables

\section{Bottom-up design}

\subsection{Structure of the regulatory control layer (Modes I and IIb)}

The unstable mode associated with the separator level is stabilized using its outlet liquid flow rate with a P-controller. Moreover, as discussed in Morud and Skogestad (1998), the reactor is normally open-loop unstable and sustained oscillations in the reactor outlet temperature may appear as a consequence of a reduction in reactor inlet pressure or temperature. They suggested to control the temperature at the inlet of the first bed using the quench flow rate before the first bed to overcome this instability. Although our model does not seem to have this feature, probably because of no radial variation of dispersion, we here follow this suggestion and close a temperature loop at this location.

To reduce drift caused by pressure changes, and also to avoid nonlinearity in control valves, we use flow controllers for the gas feed rate $F_{\text {gas }}$ and purge flow rate $F_{\text {purge }}$.

The regulatory control layer is then designed as follows:

1. Flow control of gas feed rate $F_{\text {gas }}$.

2 . Flow control of purge flow rate $F_{\text {purge. }}$

3. First-bed inlet temperature $T_{\text {bed } 1}$ with quench flow rate before the first bed $F_{\text {bed1 }}$.

4. Separator level $L_{\text {sep }}$ using its liquid outlet flow rate $F_{\text {prod }}$.

\subsection{Structure of the supervisory control layer}

Mode I: Keep the following at constant (optimal) values: feed compressor power $W_{\mathrm{K}-401}$, recycle compressor power $W_{\mathrm{K}-402}$, and purge flow rate $F_{\text {purge,sp. These are all manipulated variables, so no }}$ additional control loops are needed.

Mode IIb: Keep the compressors (K-401 and K-402) at maximum power. With the two remaining inputs $u=\left\{F_{\text {gas,sp }}, F_{\text {purge,sp }}\right\}$ we control $y=\left\{P_{\text {rin }}, y_{\mathrm{CH}_{4} \text {,purge }}\right\}$ at constant optimal set points. Suggested pairings are $F_{\text {gas,sp }}-P_{\text {rin }}$ and $F_{\text {purge,sp }}-y_{\mathrm{CH}_{4} \text {,purge }}$.

Table 12

Loss by keeping the variables in set $\mathrm{S}_{1} \mathrm{IIb}$ in Table 11 at their nominal optimal set points for Mode IIb

\begin{tabular}{|c|c|c|c|c|c|}
\hline \multirow[t]{2}{*}{ Disturbance } & \multicolumn{2}{|l|}{ Optimal } & \multicolumn{2}{|l|}{ With $S_{1}$ IIb } & \multirow[t]{2}{*}{ Loss ( $\mathrm{k} \$ /$ year) } \\
\hline & Feed rate $(\mathrm{kg} / \mathrm{h})$ & Profit (k\$/year) & Feed rate $(\mathrm{kg} / \mathrm{h})$ & Profit (k\$/year) & \\
\hline D3 & 87,595 & 75,955 & 87,759 & 75,421 & 534 \\
\hline D4 & 87,502 & 75,986 & 87,832 & 75,410 & 576 \\
\hline D5 & 87,663 & 75,887 & 87,715 & 75,334 & 553 \\
\hline D6 & 89,490 & 74,216 & 91,563 & 73,564 & 652 \\
\hline D7 & 89,114 & 74,583 & 90,892 & 73,971 & 612 \\
\hline D8 & 89,529 & 78,675 & 88,263 & 77,990 & 685 \\
\hline D9 & 90,752 & 79,258 & 89,536 & 78,627 & 631 \\
\hline Average & & & & & 606 \\
\hline
\end{tabular}

Table 13

Tuning parameters for the regulatory loops (Modes I and IIb)

\begin{tabular}{|c|c|c|c|c|c|c|}
\hline \multirow[t]{2}{*}{ Tag $^{\mathrm{a}}$} & \multirow[t]{2}{*}{ Input } & \multirow[t]{2}{*}{ Output } & \multicolumn{2}{|l|}{ Set point } & \multicolumn{2}{|c|}{ PI-controller parameters } \\
\hline & & & Mode I & Mode IIb & $K_{\mathrm{c}}(\% / \%)$ & $\tau_{\mathrm{I}}(\min )$ \\
\hline FC1 & $V_{1}$ & $F_{\text {gas }}(\mathrm{kg} / \mathrm{h})$ & 71,000 & $87,250^{\mathrm{b}}$ & 6.75 & 0.39 \\
\hline FC2 & $V_{2}$ & $F_{\text {purge }}(\mathrm{kg} / \mathrm{h})$ & 43 & $366^{\mathrm{b}}$ & 5.05 & 0.60 \\
\hline TC1 & $V_{4}$ & $T_{\text {bed } 1}\left({ }^{\circ} \mathrm{C}\right)$ & 306 & 293 & 8.05 & 1.60 \\
\hline LC1 & $V_{3}$ & $L_{\text {sep }}(\mathrm{m})$ & 2.5 & 2.5 & 2.00 & - \\
\hline
\end{tabular}

a See tags in Fig. 6.

b Nominal value. Set point set by outer loop. 


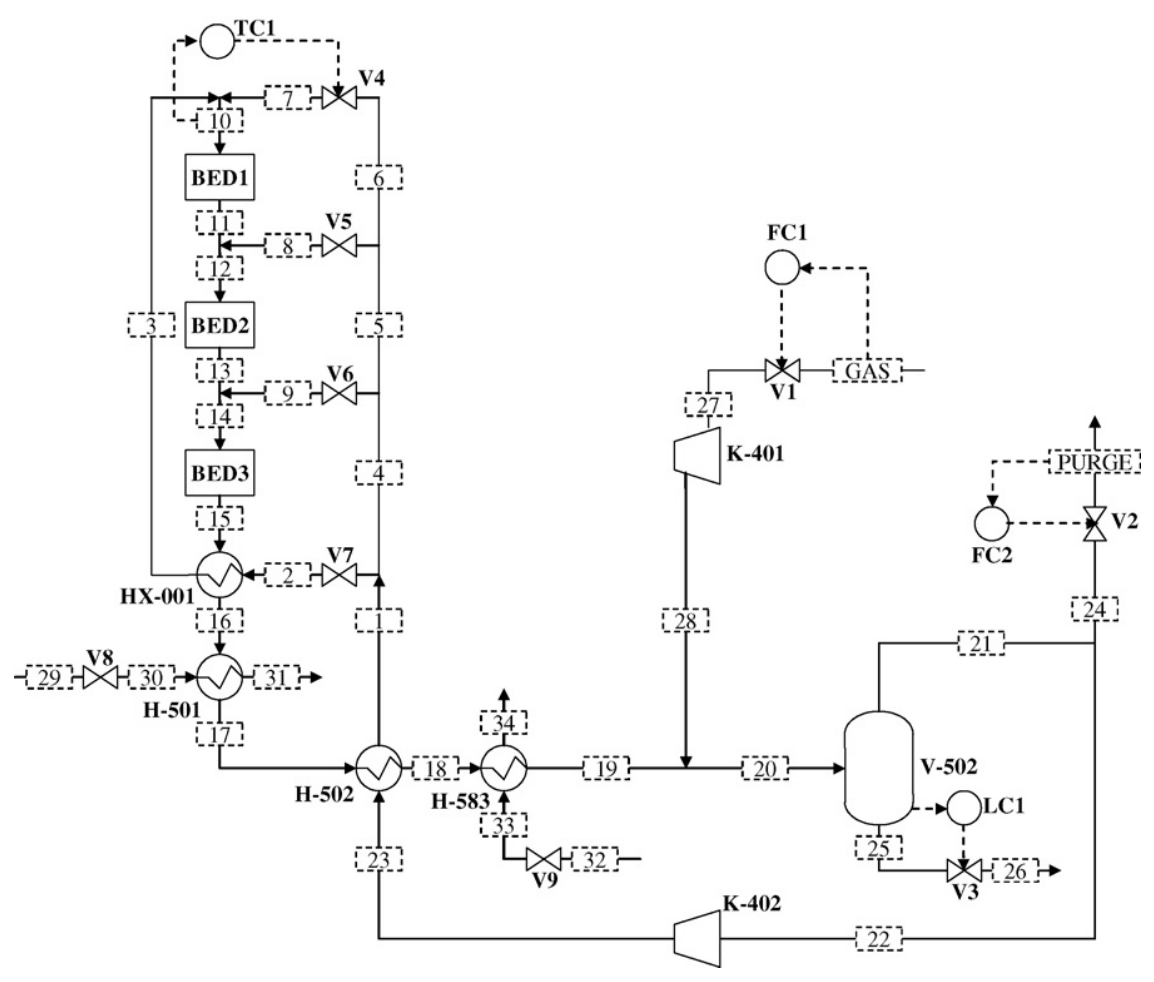

Fig. 6. Ammonia synthesis process flowsheet with controllers installed (Mode I).

Figs. 6 and 7 depict the final control structures for Modes I and IIb, respectively.

\subsection{Switching between Mode I and Mode IIb}

The transition between Modes I and IIb involves changing the set points for $W_{\mathrm{K}-401}, W_{\mathrm{K}-402}$, and $T_{\mathrm{bed} 1}$ from the nominally optimal for
Mode I to the maximum throughput set point in Mode IIb. In addition, we need to close two loops: $F_{\text {gas,sp }}-P_{\text {rin }}$ and $F_{\text {purge,sp }}-y_{\mathrm{CH}_{4} \text {, purge }}$.

\subsection{Controller tuning}

The regulatory loops selected above are closed and tuned one at the time in a sequential manner (starting with the fastest loops). Aspen Dynamics ${ }^{\mathrm{TM}}$ has an open-loop test capability that was used

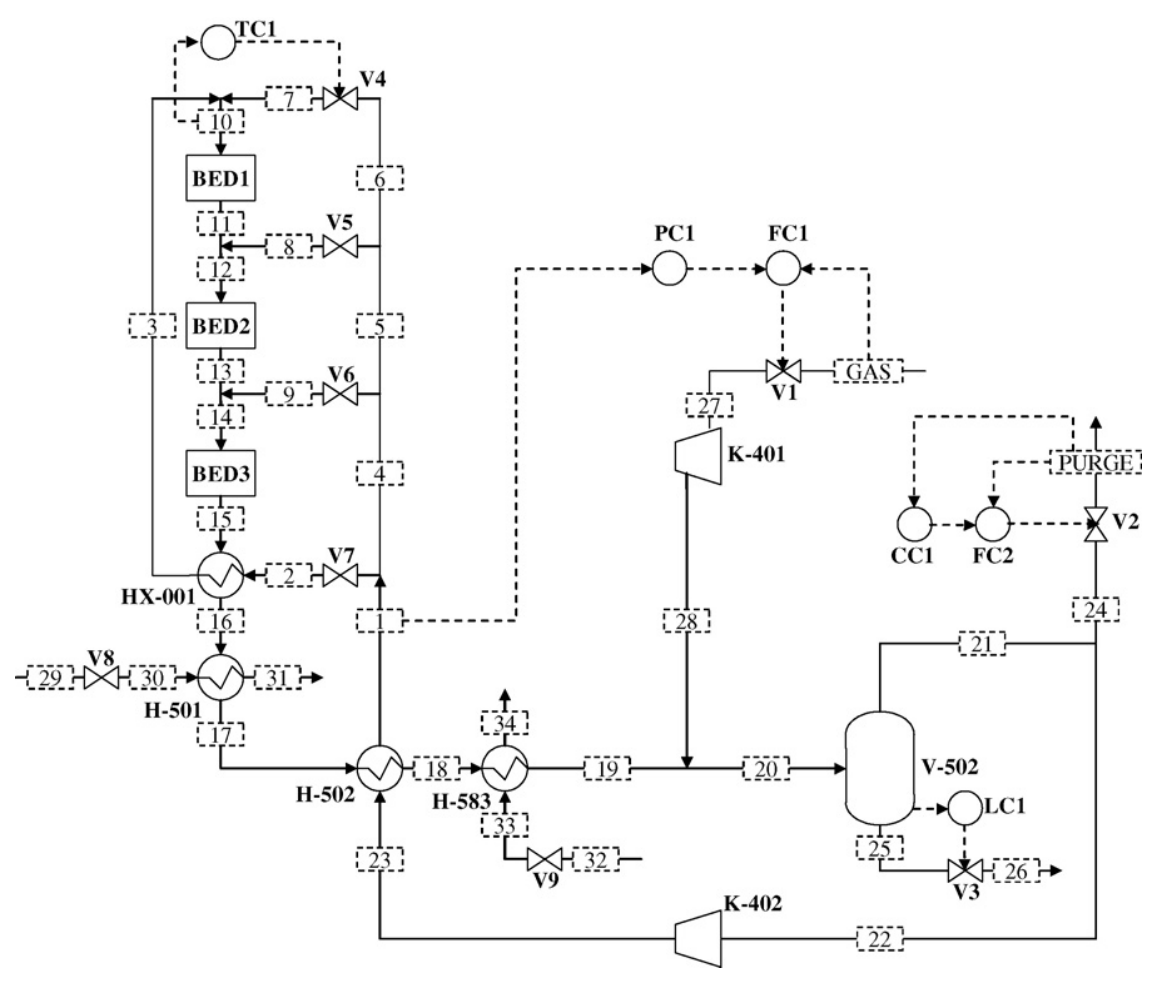

Fig. 7. Ammonia synthesis process flowsheet with controllers installed (Mode IIb). 
to determine a first-order plus delay model from $u$ to $y$. Based on the model parameters, we used the SIMC tuning rules (Skogestad, 2003) to design the PI-controllers:

$K_{\mathrm{c}}=\frac{1}{k} \frac{\tau}{\tau_{\mathrm{c}}+\theta}, \quad \tau_{\mathrm{I}}=\min \left[\tau, 4\left(\tau_{\mathrm{c}}+\theta\right)\right]$

where $k, \tau$, and $\theta$ are the gain, time constant, and effective time delay, respectively. In our case, we choose $\tau_{\mathrm{c}}=\theta$ to ensure robustness and small input variation.

The gain $K_{\mathrm{c}}$ and integral time $\tau_{\mathrm{I}}$ for the regulatory controllers (Modes I and IIb) are given in Table 13, and for supervisory controllers (Mode IIb) in Table 14. There is no need for supervisory control in Mode I (given feed) because the purge flow ( $\left.F_{\text {purge }}\right)$ and the two compressor powers $\left(W_{\mathrm{K}-401}\right.$ and $\left.W_{\mathrm{K}-402}\right)$ are simply set constant.
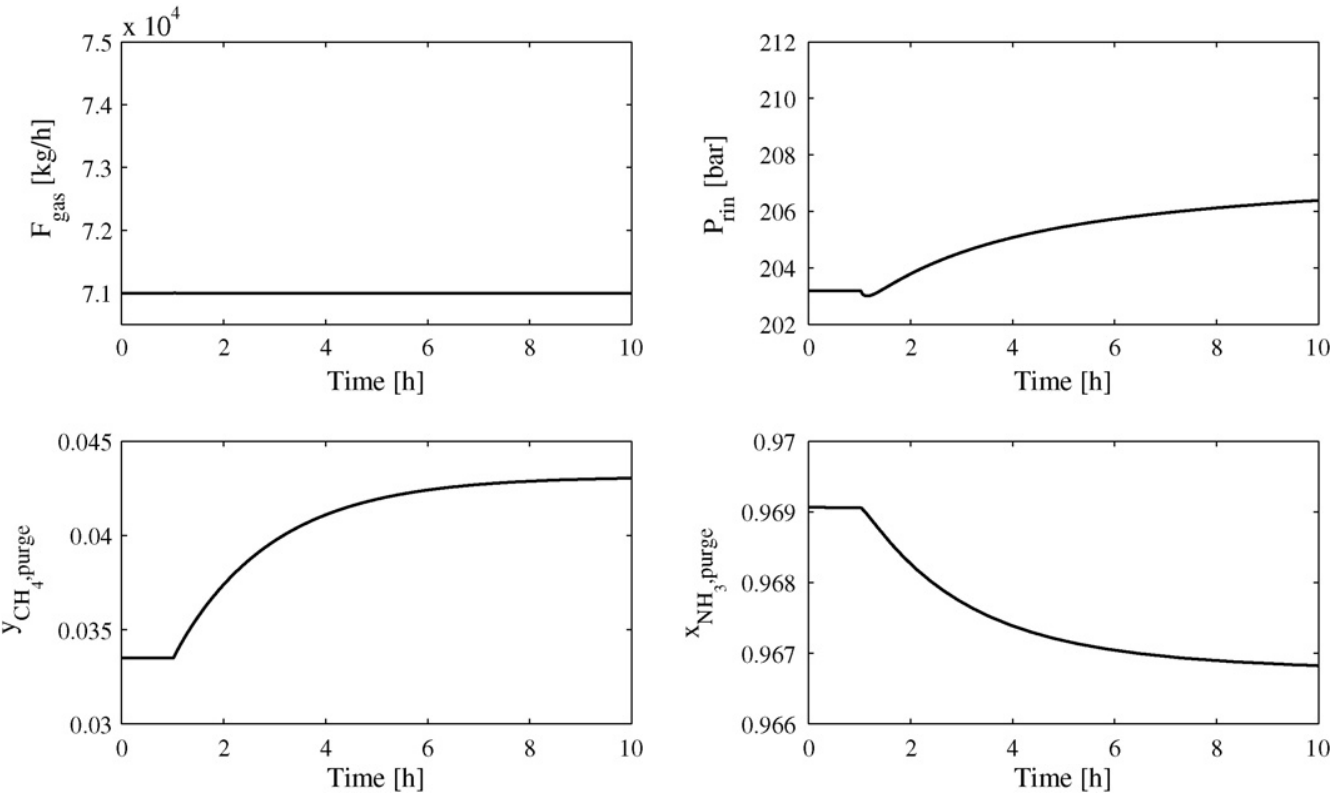

Fig. 8. Mode I: Dynamic response of selected variables for disturbance Dyn1
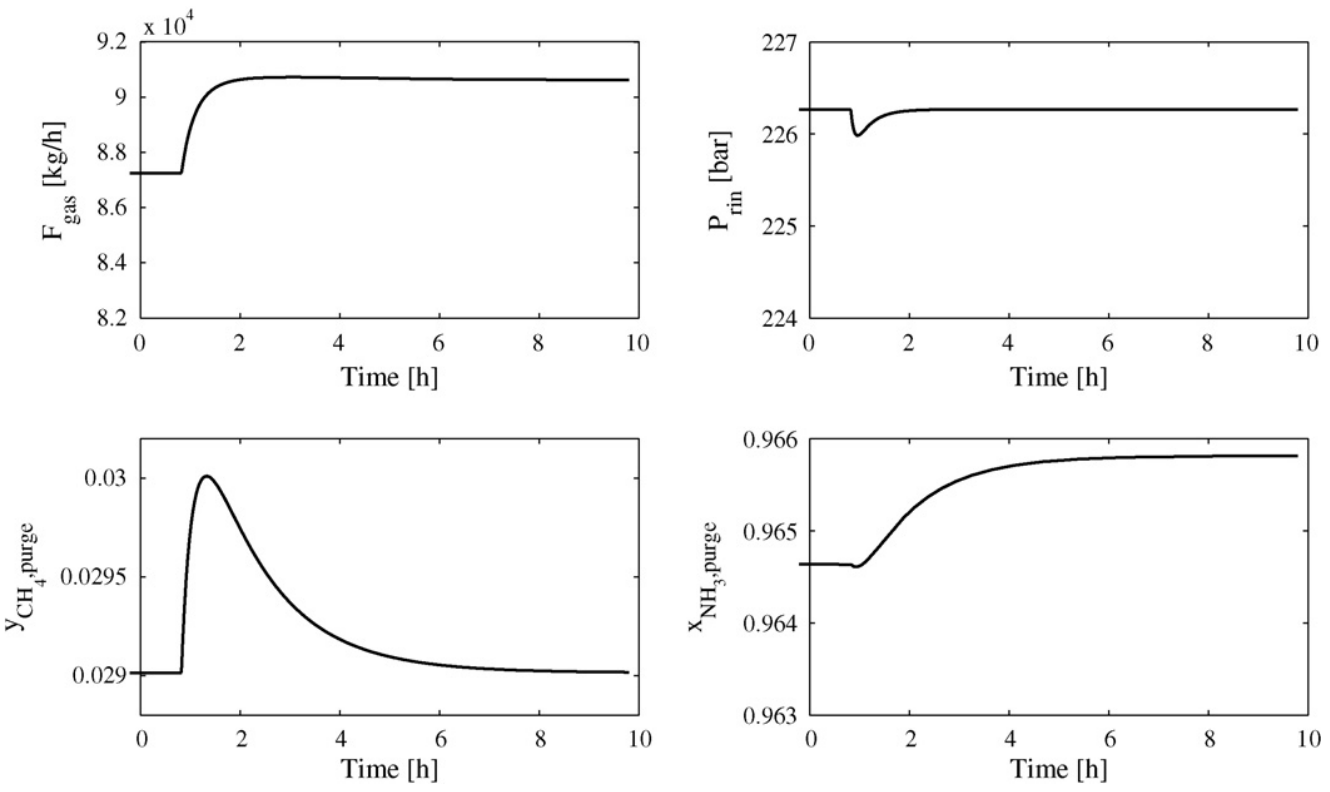

Fig. 9. Mode IIb: Dynamic response of selected variables for disturbance Dyn1. 

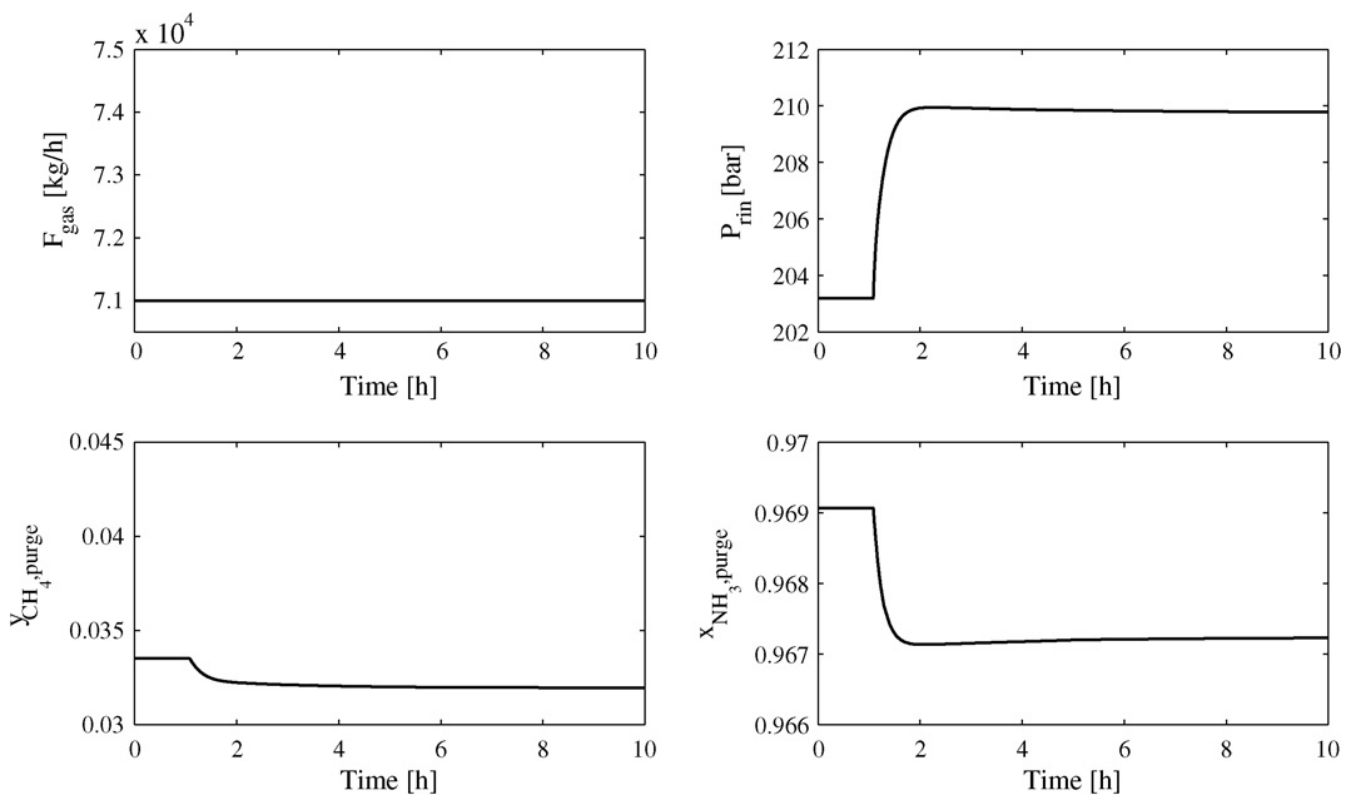

Fig. 10. Mode I: Dynamic response of selected variables for disturbance Dyn2.
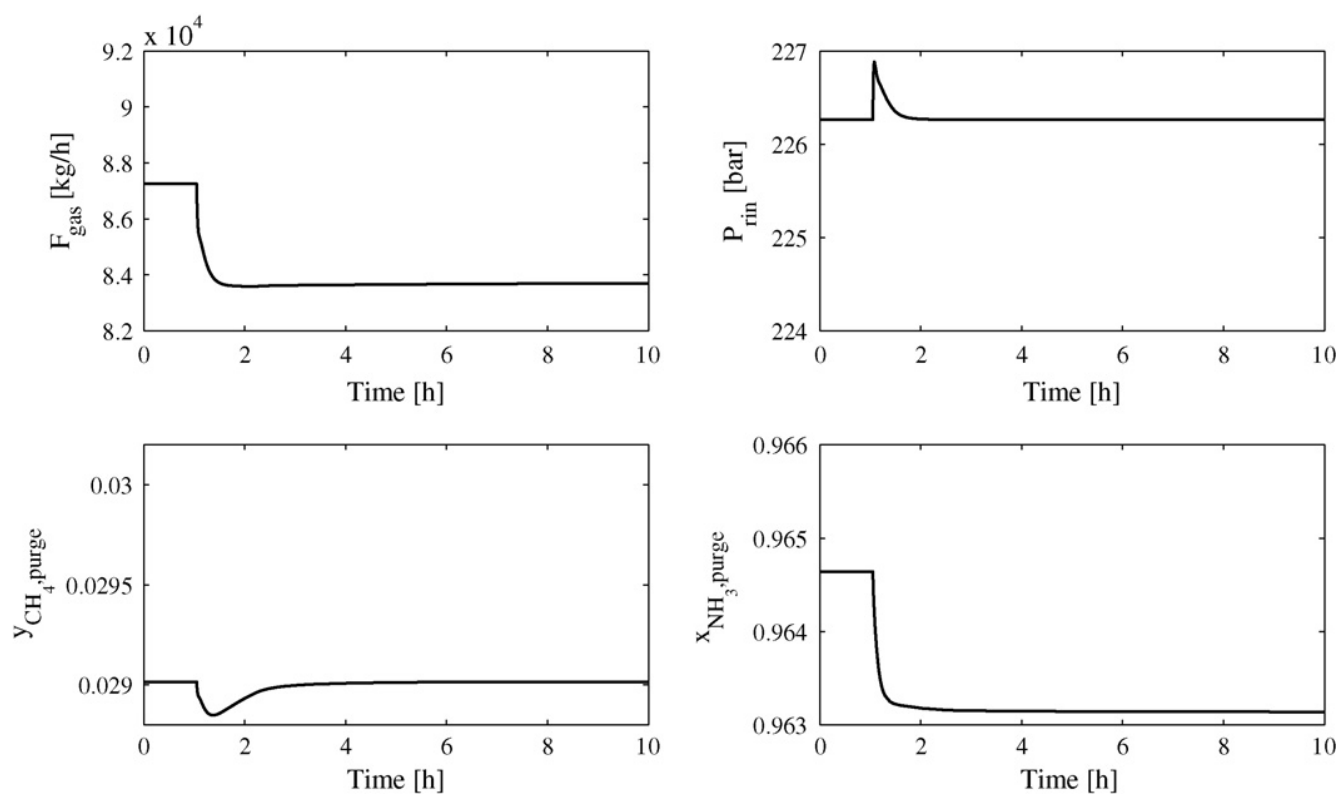

Fig. 11. Mode IIb: Dynamic response of selected variables for disturbance Dyn2.

Table 15

Disturbances to the effect of dynamic simulations for Modes I and IIb

\begin{tabular}{llll}
\hline No. & Description & Nominal & Disturbance \\
\cline { 3 - 4 } & & Mode I & Mode IIb \\
\hline Dyn1 & Mole fraction of $\mathrm{CH}_{4}$ in the gas feed & 0.0033 & 0.0033 \\
Dyn2 & Cooling water temperature in $\mathrm{H}-583\left({ }^{\circ} \mathrm{C}\right)$ & 15 & 15 \\
Dyn3 & Compressor power $W_{\mathrm{K}-401}(\mathrm{~kW})$ & 19,800 & $+0.0010^{\mathrm{a}}$ \\
Dyn4 & Gas feed rate $F_{\text {gas }}(\mathrm{kg} / \mathrm{h})$ & 71,000 & 25,000 \\
\hline
\end{tabular}

a Mole fraction of $\mathrm{H}_{2}$ in the gas feed is reduced by the same amount.

b Gas feed rate disturbance for Mode IIb considered as measurement error. 

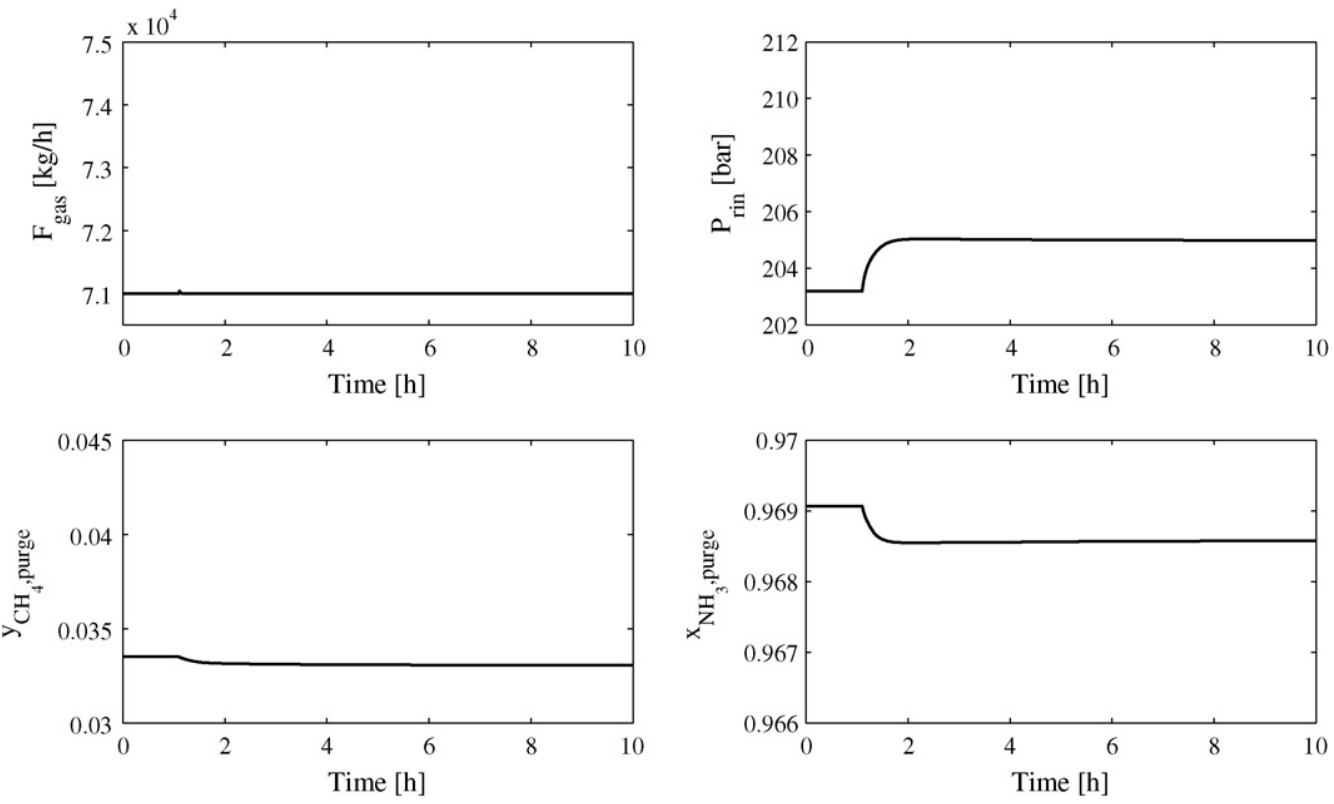

Fig. 12. Mode I: Dynamic response of selected variables for disturbance Dyn3.
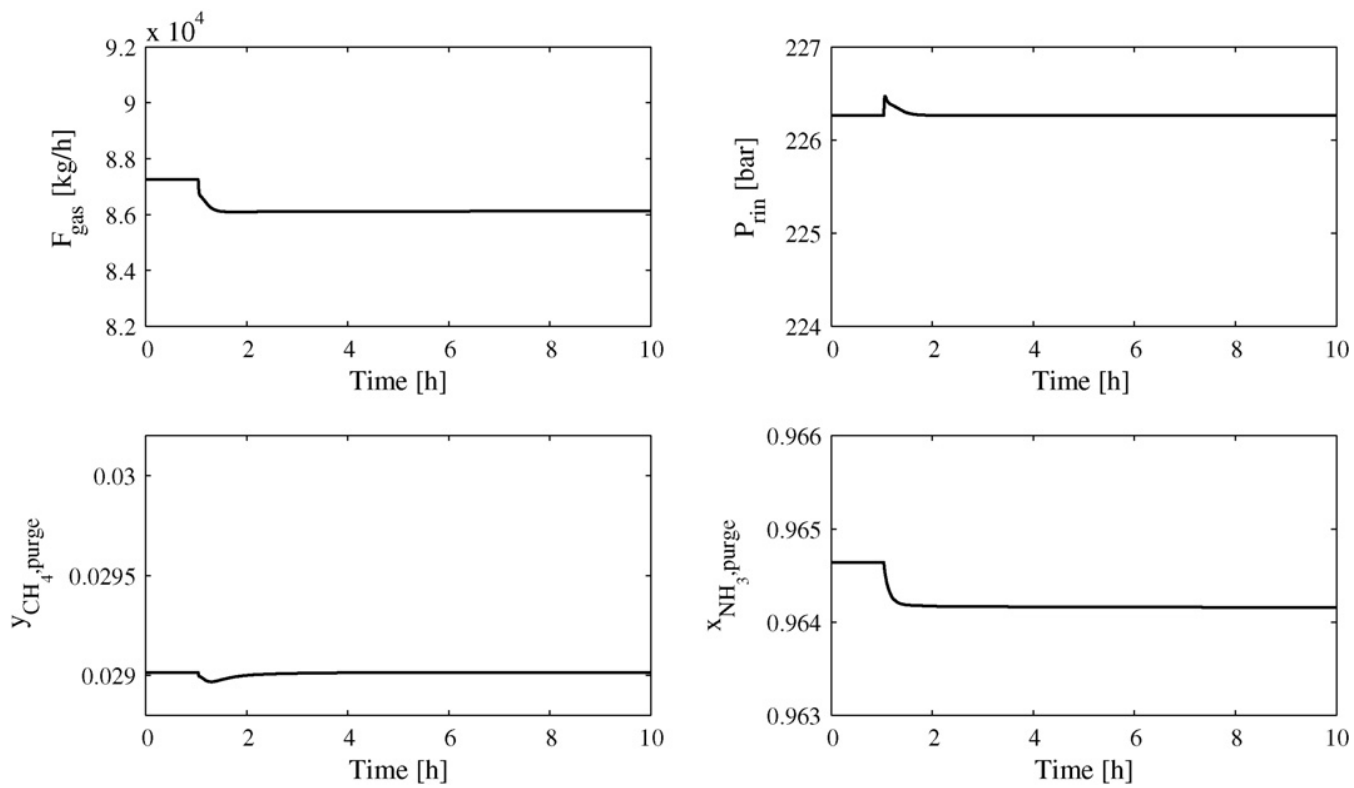

Fig. 13. Mode IIb: Dynamic response of selected variables for disturbance Dyn3.

Table 16

Specifications for the ammonia reactor model in Aspen Plus ${ }^{\mathrm{TM}}$

\begin{tabular}{|c|c|c|c|}
\hline Specification & Bed 1 & Bed 2 & Bed 3 \\
\hline Reactor type & Adiabatic & Adiabatic & Adiabatic \\
\hline Length (m) & 2.13 & 3.07 & 4.84 \\
\hline Diameter (m) & 2.00 & 2.00 & 2.00 \\
\hline Bed voidage & 0.33 & 0.33 & 0.33 \\
\hline Particle density $\left(\mathrm{kg} / \mathrm{m}^{3}\right)$ & 2200 & 2200 & 2200 \\
\hline Heat transfer between catalyst and process fluid ${ }^{a}$ & Neglected & Neglected & Neglected \\
\hline Equipment heat capacity $(\mathrm{kJ} /(\mathrm{kg} \mathrm{K}))^{\mathrm{b}}$ & 0.50 & 0.50 & 0.50 \\
\hline
\end{tabular}

a Simulations showed the heat transfer between catalyst and process fluid could be neglected.

b We assumed the default values given in the model dynamic specification tab. 

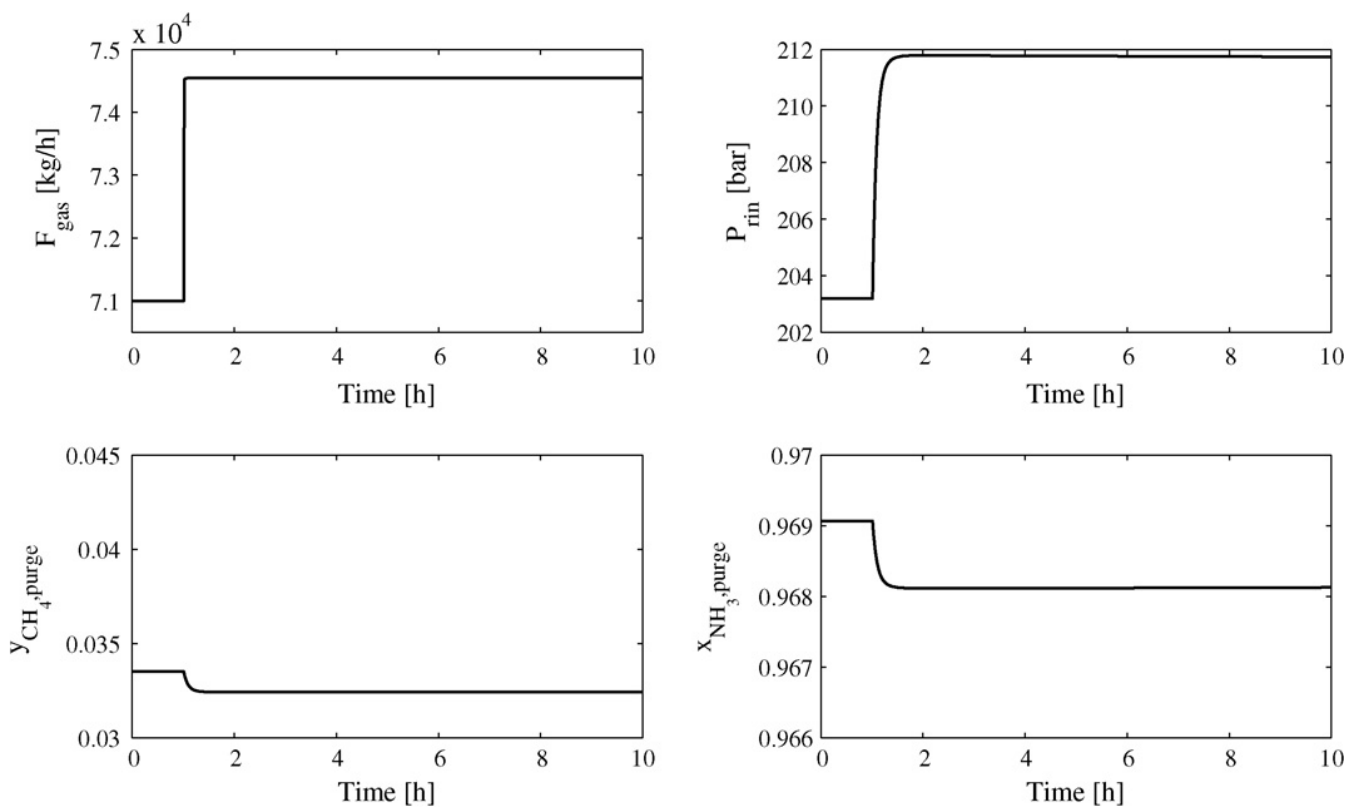

Fig. 14. Mode I: Dynamic response of selected variables for disturbance Dyn4.
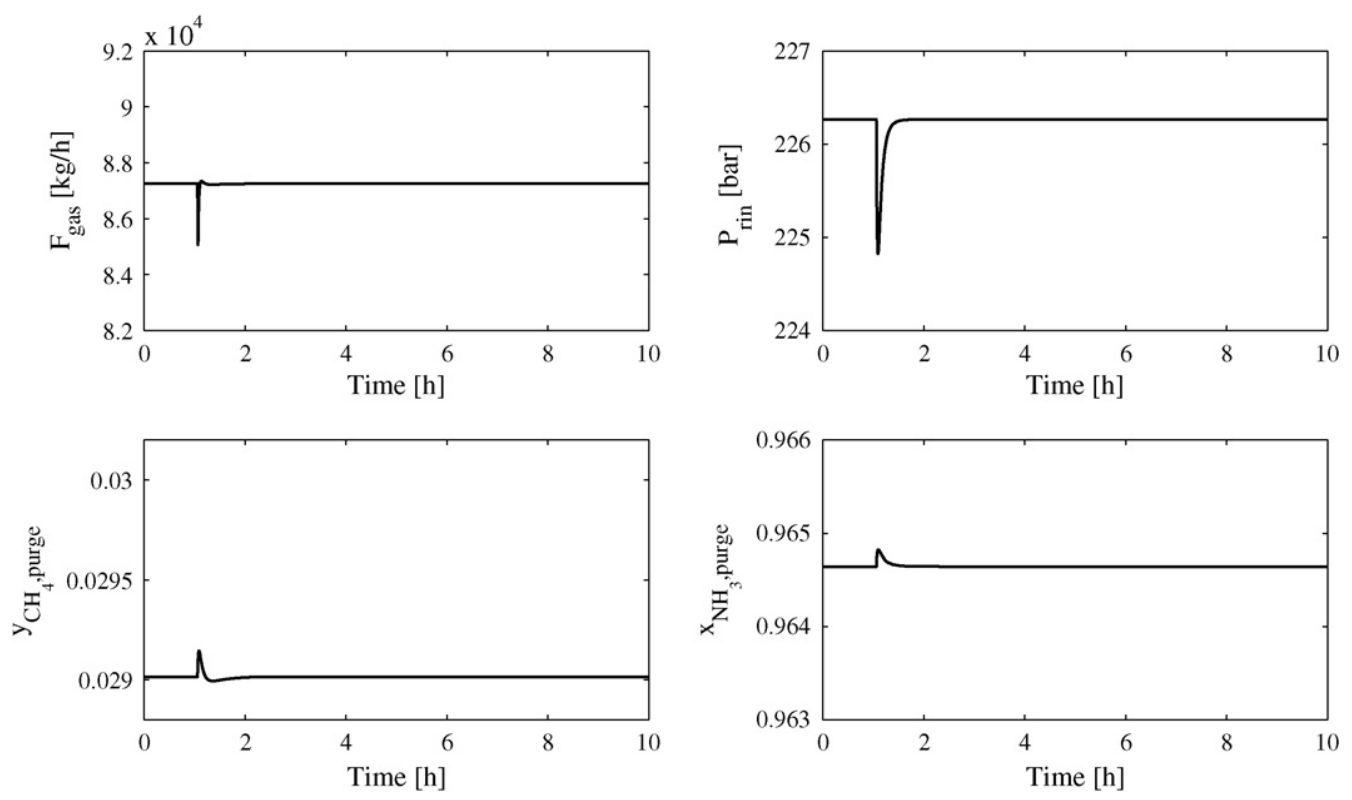

Fig. 15. Mode IIb: Dynamic response of selected variables for disturbance Dyn4.

turbances are applied $1 \mathrm{~h}$ after the beginning of each simulation run.

It can be seen from Figs. 8 and 15 that the product purity does not change significantly in both modes of operation. The reason for this is that ammonia is satisfactorily separated from the other components at all conditions. Moreover, as discussed above, in Mode I the pressure of the system is allowed to fluctuate without causing the process to drift away from its nominally optimal operating condition. In Mode IIb, the pressure is tightly controlled. In general, the dynamic responses for both modes are satisfactory with settling time of about $4 \mathrm{~h}$, except for disturbance Dyn 1 which seems to be the most difficult disturbance to reject. But this was expected since composition is usually slower than other variables, e.g., flow, pressure, and temperature. The reactor inlet/outlet tem- perature responses are not shown, but they perform very nicely with a maximum change of about $8^{\circ} \mathrm{C}$.

Multivariable control would improve the performance of this system, but we find that the dynamic performance with decentralized control is acceptable.

\section{Conclusion}

This paper discussed the application of the plantwide design procedure of Skogestad (2004) to the ammonia synthesis process. It has been found that is not economically attractive to operate the process beyond the production rate determined by the "economic" bottleneck corresponding to the maximum gas feed rate. By applying the self-optimizing technique of Skogestad (2000), we also 
found that it is (near) optimal to operate the supervisory control layer by keeping constant set point policy for the feed compressor power, recycle compressor power, and purge flow rate when the gas feed rate is given (Mode I), which corresponds to the practice currently adopted in industrial ammonia synthesis plants. In case of optimized throughput (Mode IIb), the pressure of the system and the mole fraction of $\mathrm{CH}_{4}$ should be controlled to achieve (near) optimal operation. The regulatory layer is enhanced by controlling the reactor temperature so to avoid the deteriorating effects of oscillations caused by variations in the reactor inlet conditions (temperature and/or pressure) (Morud \& Skogestad, 1998).

\section{Appendix A}

Table 16 shows the main options and parameters used for modeling the ammonia reactor in Aspen Plus ${ }^{\mathrm{TM}}$. The more detailed Aspen Plus ${ }^{\mathrm{TM}}$ (.bkp) file is also available at http://www.nt.ntnu.no/ users/skoge/.

\section{References}

Cao, Y., \& Kariwala, V. (2008). Bidirectional branch and bound for controlled variable selection: Part I. Principles and minimum singular value criterion. Computers and Chemical Engineering, 32(10), 2306-2319.

Froment, G. F., \& Bischoff, K. B. (1990). Chemical reactor analysis and design (2nd ed.) New York: Wiley.

Maarleveld, A., \& Rijnsdorp, J. E. (1970). Constraint control on distillation columns. Automatica, 6, 51-58.

Morud, J. C., \& Skogestad, S. (1998). Analysis of instability in an industrial ammonia reactor. AIChE Journal, 44(4), 888-895.

Skogestad, S. (2000). Plantwide control: The search for the self-optimizing contro structure. Journal of Process Control, 10, 487-507.

Skogestad, S. (2002). Plantwide control: Towards a systematic procedure. Proceedings of the European Symposium on Computer Aided Process Engineering, 12 57-69.

Skogestad, S. (2003). Simple analytic rules for model reduction and PID controller tuning. Journal of Process Control, 13, 291-309.

Skogestad, S. (2004). Control structure design for complete chemical plants. Computers and Chemical Engineering, 28, 219-234.

Skogestad, S., \& Postlethwaite, I. (2005). Multivariable feedback control: Analysis and design. Chichester, UK: John Wiley \& Sons. 